\title{
An experimental and kinetic modeling study on dimethyl carbonate (DMC) pyrolysis and combustion
}

\author{
Wenyu Sun ${ }^{\mathrm{a}}$, Bin Yang ${ }^{\mathrm{a}}{ }^{*}$, Nils Hansen ${ }^{\mathrm{b}}$, Charles K. Westbrook ${ }^{\mathrm{c}}$, Feng Zhang ${ }^{\mathrm{d}}$, \\ Gao Wang ${ }^{\mathrm{d}}$, Kai Moshammer ${ }^{\mathrm{b}, \mathrm{e}}$, Chung K. Law ${ }^{\mathrm{a}, \mathrm{f}}$ \\ ${ }^{a}$ Center for Combustion Energy and Department of Thermal Engineering, Tsinghua University, Beijing, 100084, $P$. \\ R. China \\ ${ }^{b}$ Combustion Research Facility, Sandia National Laboratories, Livermore, CA 94551, USA \\ ${ }^{c}$ Lawrence Livermore National Laboratory, Livermore, CA 94550, USA \\ ${ }^{d}$ National Synchrotron Radiation Laboratory, University of Science and Technology of China, Hefei, Anhui \\ 230029, P.R. China \\ ${ }^{e}$ Department of Chemistry, Bielefeld University, D-33615 Bielefeld, Germany \\ ${ }^{f}$ Department of Mechanical and Aerospace Engineering, Princeton University, Princeton, NJ 08544, USA
}

\begin{abstract}
Dimethyl carbonate (DMC) is a promising oxygenated additive or substitute for hydrocarbon fuels, because of the absence of $\mathrm{C}-\mathrm{C}$ bonds and the large oxygen content in its molecular structure. To better understand its chemical oxidation and combustion kinetics, flow reactor pyrolysis at different pressures (40, 200 and 1040 mbar) and low-pressure laminar premixed flames with different equivalence ratios (1.0 and 1.5) were investigated. Mole fraction profiles of many reaction intermediates and products were obtained within estimated experimental uncertainties. From theoretical calculations and estimations, a detailed kinetic model for DMC pyrolysis and high-temperature combustion consisting of 257 species and 1563 reactions was developed. The performance of the kinetic model was then analyzed using detailed chemical composition information, primarily from the present measurements. In addition, it was examined against the chemical structure of an opposed-flow diffusion flame, relying on global combustion properties such as the ignition delay times and laminar burning velocities. These extended comparisons yielded overall satisfactory agreement, demonstrating the applicability of the present model over a wide range of high-temperature conditions.
\end{abstract}

Keywords: Dimethyl carbonate (DMC); Pyrolysis; Laminar premixed flame; Kinetic model

\footnotetext{
* Corresponding author. E-mail: byang@ $@$ tsinghua.edu.cn, Tel: +86-10-62796631.
} 


\section{Introduction}

Oxygenated hydrocarbon fuels derived from biomass are attracting considerable attention either as replacements of, or additives to, conventional hydrocarbon fuels in internal combustion engines. They offer potential benefits as renewable fuels, with a long-term zero $\mathrm{CO}_{2} \mathrm{debt}$, and the tendency to reduce soot formation [1-3]. Dimethyl carbonate $\left[\mathrm{CH}_{3} \mathrm{OC}(=\mathrm{O}) \mathrm{OCH}_{3}, \mathrm{DMC}\right]$, being non-toxic and highly miscible with diesel fuels, is one of such promising clean fuels. Carbon-carbon bonds are absent in the DMC molecular structure which contains three oxygen atoms. In a diesel engine study, Miyamoto et al. [2] found that the extent of soot reduction mainly depended on the amount of oxygen present in the fuel. Furthermore, when the oxygen content of the fuel was above $25 \%$ by mass, soot emission fell beyond detection. Although the fuel's structure and the particular combustion conditions are of non-negligible influence on the emissions, it is worthwhile to consider the high oxygen content (53\% by mass) of DMC: it suggests that DMC addition in small amounts could achieve significant soot reduction. From laboratory experiments $[4,5]$ to practical engine operations [6-9], extensive studies have been conducted on the effects of adding DMC to hydrocarbon fuels. Specifically, Rubino and Thomson [4] used a counter-flow propane/air diffusion flame to study the inhibition of soot precursor formation by adding oxygenated compounds including DMC. They observed a remarkable reduction of soot precursors such as acetylene $\left(\mathrm{C}_{2} \mathrm{H}_{2}\right)$ and benzene $\left(\mathrm{C}_{6} \mathrm{H}_{6}\right)$, as well as a linear relationship between the $\mathrm{C}_{2} \mathrm{H}_{2}$ concentration and the additive's oxygen and $\mathrm{C}-\mathrm{C}$ bond content. Furthermore, Chen et al. [5] found that concentrations of most $\mathrm{C}_{1}-\mathrm{C}_{5}$ hydrocarbon intermediates decreased in low-pressure laminar premixed $n$-heptane flames with DMC addition. In practical engine studies of blends of DMC and diesel [6-8] or gasoline [9] fuels, hydrocarbons (HC), CO [6, 9], particulate matter (PM) [7] and smoke [8] concentrations were found to decrease significantly with DMC addition. However, these benefits are achieved at the expense of increased emissions of oxygenated pollutants such as formaldehyde $\left(\mathrm{CH}_{2} \mathrm{O}\right)[3]$.

Using DMC as a neat fuel, Sinha and Thomson [10] measured the chemical structure of a DMC/air opposed flow diffusion flame and proposed possible oxidation pathways. The first detailed chemical kinetic model for DMC was established by Glaude et al. [11] (hereafter referred to as the Glaude model), which well reproduced the measured diffusion flame structure of [10]. In developing their model, however, analogy was taken as the principal method for rate coefficients evaluation. Indeed, the development of DMC kinetic models has been slowed by the dearth of elementary reaction studies. Recently, the rate coefficients of DMC thermal decomposition processes and the bimolecular reactions of $\mathrm{H} / \mathrm{O}$ with $\mathrm{DMC}$ were determined by Peukert et al. [12, 13] through shock tube measurements in conjunction with master equation analysis. Furthermore, 
Bardin et al. [14] measured the burning velocities of DMC/air flames and simulated their

measurements with the Glaude model [11], showing significant over-prediction of the experimental results, while $\mathrm{Hu}$ et al. [15], investigated DMC ignition was investigated in a shock tube, and modified the Glaude model (referred to as the $\mathrm{Hu}$ model) to better reproduce the measured ignition delay times.

It may be recognized that while both the Glaude model [11] and the Hu model [15] can predict some specific experimental results, neither of them has been extensively validated and as such, they are of limited applicability. The goal of the present study is therefore to develop a more extensively validated kinetic model for the high temperature chemistry of DMC. A number of conditions were investigated in a combined theoretical, experimental and modeling approach. Specifically, we have performed theoretical calculations to acquire pressure-dependent rate coefficients for unimolecular reactions of DMC decomposition. Furthermore, the mole fraction profiles of intermediates and products during DMC pyrolysis at different pressures were obtained experimentally, using a GC system. In addition, extensive sets of species profiles were measured in two DMC laminar premixed flames with different equivalence ratios using molecular beam mass spectrometry (MBMS). Based on these results, a new detailed kinetic model for the high-temperature DMC pyrolysis and oxidation is proposed. All available experimental measurements in the literature and the new measurements from the present study were employed in the model validation. The comparisons between the model predictions and experimental data were satisfactory for the detailed species composition as well as the global combustion parameters. Reaction paths and some kinetic characteristics of DMC pyrolysis and oxidation were also explored with the new kinetic model.

\section{Experimental}

Systematic chemical composition measurements were performed under pyrolysis and premixed laminar flame conditions. The conditions for these current experiments are summarized in Table 1. To facilitate comparison, the table also includes the experimental conditions for previous DMC-related studies [10, 14, 15]. These experimental data, including both global combustion properties and chemical details, are then used to examine a newly developed detailed kinetic model which will be discussed in the Kinetic Modeling section.

\subsection{Flow reactor pyrolysis}

A laminar flow reactor combined with a gas chromatography (GC) system was used to study the DMC pyrolysis process at selected pressures. In a previous study [16], species mole fractions measured with GC and photoionization mass spectrometry (PIMS) showed very good agreement with each other, demonstrating the feasibility of the GC technique in similar pyrolysis studies. The 
detailed description of the experimental apparatus was given elsewhere [17]. In brief, the apparatus consists of a pyrolysis chamber, the sampling system and a GC (Bruker 450-GC) system. The schematic diagram of the pyrolysis apparatus is given in Fig. 1. In the pyrolysis chamber, a mixture of argon and vaporized DMC with respective flow rates of 980 standard c.c./minute (SCCM) and 20 SCCM was fed to a crystalline $\alpha$-alumina $\left(\alpha-\mathrm{Al}_{2} \mathrm{O}_{3}\right)$ flow tube heated by a heating wire. This material is chosen because it does not have a significant catalytic effect on the pyrolysis of hydrocarbon and oxygenated fuels $[18,19]$. The inner diameter (ID) of the flow tube is $7 \mathrm{~mm}$ and the length is $229 \mathrm{~mm}$. The pyrolysis products was sampled at $10 \mathrm{~mm}$ downstream of the outlet by a 3-mm-ID quartz tube. After sampling, the pyrolysis products entered the six-way valve of the GC through a steel transfer line, which was maintained at $473 \mathrm{~K}$ to avoid condensation. Three different pressures, 40, 200 and ,1040 mbar (30,150 and 780 Torr), were investigated, and they could be treated as constant along the flow tube according to respective calculations [20]. The products were identified by a mass spectrometer (Bruker, 320-MS) coupled with the GC. A flame ionization detector (FID) was used to quantify the stable organic compounds, and thermal conductivity detection (TCD) was employed for $\mathrm{CO}_{2}$ and $\mathrm{CO}$. Calibration was performed with a gas mixture of known composition and the measured response factors at different pressures are presented in Table S1 in the Supplemental material. The response factor is defined here as the proportionality coefficient between the signal intensity and the mole fraction of a specific species. The carbon balance was checked to ensure the reliability of the quantification. The temperature profile along the centerline of the flow tube was measured with an S-type thermocouple at a total argon flow rate of 1000 SCCM; three profiles are shown in Fig. 1 (b). A temperature profile will then be denoted by its maximum temperature $\left(\mathrm{T}_{\max }\right)$ in the following, and the mole fractions of the pyrolysis species at the sampling point will be given as functions of this temperature $\left(T_{\max }\right)$. The residence time varied with temperature and pressure because the initial total flow rate was kept constant. The calculated values at 40, 200 and 1040 mbar in the temperature range studied are $9.3 \times 10^{-3} \sim 1.2 \times 10^{-2}$, $4.9 \sim 6.8 \times 10^{-2}$ and $2.5 \sim 3.1 \times 10^{-1} \mathrm{~s}$, respectively.

In the flow reactor pyrolysis experiments, the uncertainty of the mole fraction measurements was estimated as $20 \%$. The values could be lower at 1040 mbar as signals are of higher intensity under higher pressures. The measure uncertainty factor increases to 2 for DMC when the conversion ratio reaches over $90 \%$ because the original signal becomes weak. In addition, the uncertainty in the temperature measurement was estimated to be within $\pm 30 \mathrm{~K}$.

\subsection{Low-pressure laminar premixed flame}

Further experimental work was carried out at the Advanced Light Source (ALS) of the Lawrence Berkeley National Laboratory. A detailed description of the instrument and experimental 
procedures is given elsewhere [21, 22]. Briefly, a laminar premixed flame was stabilized over a

6.0-cm-diameter stainless steel McKenna burner. The flame gases were sampled along the axis of the flame by a quartz nozzle with a $40^{\circ}$ included angle and a $200 \mu \mathrm{m}$ orifice at the tip. The formed molecular beam was crossed by the dispersed VUV light from the synchrotron, and the resulting photo-ions were mass-analyzed with a reflectron time-of-flight mass spectrometer with mass resolution $\mathrm{m} / \Delta \mathrm{m}=3500$. The integrated ion intensities for a specific mass were normalized by the photon flux, and then plotted as a function of the photon energy or distance from the burner surface, which then yielded the photoionization efficiency (PIE) or mole fraction profiles, respectively. $\mathrm{DMC} / \mathrm{O}_{2} / \mathrm{Ar}$ flames with equivalence ratios of 1.0 and 1.5 were investigated at low pressures [26.66 and 33.33 mbar (25 and 30 Torr) respectively]. The pressures were chosen to maximize flame thickness and stand-off distance while maintaining flame stability. The operating conditions are also listed in Table 1. Gas flow rates $\left(\mathrm{O}_{2}\right.$ and $\left.\mathrm{Ar}\right)$ were controlled separately by mass flow controllers, while the flow rate of liquid DMC into the vaporizer was controlled by a syringe pump.

Following the practice proposed by Cool et al. [23], the mole fractions of each species along the distance from the burner were obtained. Conservation of carbon, hydrogen and oxygen atoms was adopted in determining the mole fractions of the major species $\left(\mathrm{H}_{2} \mathrm{O}, \mathrm{H}_{2}, \mathrm{CO}, \mathrm{CO}_{2}, \mathrm{O}_{2}, \mathrm{DMC}\right.$ and $\mathrm{Ar}$ ) at equilibrium regions. For the minor species, a three-stage approach was designed to minimize interferences from fragment ions. The schematic diagram is presented in Fig. S1 of the Supplemental material. Several photon energies were selected for burner scans by considering the photoionization cross sections, species ionization energies, and appearance energies for photo fragmentations. In addition, the photoionization cross sections (PICSs), along with the mass discrimination (MD) factors used in quantification are also listed in the Supplemental material as Table S2. Flame temperature was measured using laser induced fluorescence (LIF) from naturally present $\mathrm{OH}[24,25]$ under flame conditions without the sampling cone.

For the laminar premixed flame, estimations of uncertainties are complicated, as recently reviewed [26] for this type of flame study with the PIMS method. Among all influences, probe sampling effects and the data treatment procedure are the two most prominent error sources. Disturbance from the sampling probe has always been an intriguing problem [27, 28], and some empirical practices have been discussed in the literature [29-31]. Recognizing that the fuel-rich flame could be more strongly influenced by the sampling process due to its thicker reaction zone and that the extent to probe effects could be different for different species [27], the measured $\mathrm{CO}$ and $\mathrm{CO}_{2}$ profiles of the fuel-rich flame were shifted downstream $1 \mathrm{~mm}$ and $1.5 \mathrm{~mm}$, respectively. And the profiles for other major species are presented without any shifts. It should be noted that the data less than $1 \mathrm{~mm}$ away from the burner surface should be used with caution, as distortion is likely 
more severe near the burner surface [32]. The error of the LIF temperature measurement was estimated to be $\pm 100 \mathrm{~K}[33]$. When performing model simulations, we followed the practice of shifting the measured temperature profiles [27] by $0.5 \mathrm{~mm}$ and $1 \mathrm{~mm}$ downstream of the $\phi=1.0$ and 1.5 flame respectively. Although the measured temperature profiles are crucial input parameters for the simulations, in a similar flame study [34] it was reported that mechanistic conclusions were not significantly altered by a temperature uncertainty of $200 \mathrm{~K}$.

The review of [26] employed specific examples to demonstrate the uncertainty in identification and separation of minor species, especially those involving isomers. Apart from the issues discussed in this review, two additional aspects also need to be considered. The first issue concerns the elimination of interference from the background $\mathrm{H}_{2} \mathrm{O}$ signal. Usually half of the signal at the initial point was taken as the background $\mathrm{H}_{2} \mathrm{O}$ and excluded from the signal of each sampling point. This empirical practice was supported by our previous study of a $\mathrm{D}_{2} / \mathrm{O}_{2}$ flame. It should be mentioned, however, that this approach entailed an uncertainty of $30 \%$ for the peak mole fraction of $\mathrm{C}_{2} \mathrm{H}_{2}$, because the mole fraction of $\mathrm{H}_{2} \mathrm{O}$ was taken as the primary reference in calculating the minor species profiles. This uncertainty would then propagate to other minor species through the quantification procedure. The other issue concerns the accuracy of the photoionization cross section (PICS) as a crucial parameter in converting the signal intensity to mole fraction for the flame species. Again, the measured uncertainty would propagate directly to that of the mole fractions. As shown in Table S2, the PICSs for all flame species were chosen carefully. Particularly, we always used the PICSs measured using the photon beam with similar energy resolution as that of our flame study. For example, the PICSs of $\mathrm{C}_{2} \mathrm{H}_{2}, \mathrm{C}_{2} \mathrm{H}_{4}, \mathrm{C}_{3} \mathrm{H}_{4}-\mathrm{a}, \mathrm{C}_{3} \mathrm{H}_{4}-\mathrm{p}, \mathrm{CH}_{3} \mathrm{CHO}, \mathrm{CH}_{2} \mathrm{CO}, \mathrm{CH}_{3} \mathrm{OCH}_{3}, \mathrm{C}_{4} \mathrm{H}_{2}$, $\mathrm{C}_{4} \mathrm{H}_{4}, \mathrm{C}_{4} \mathrm{H}_{6}$ measured by Cool et al. [35], Wang et al.[36] and Yang et al. [37] at the same beamline at the ALS were selected, which were claimed to be within an uncertainty of $20 \%$.

Given these influences, different uncertainty factors for different species at different spatial positions were estimated based on the recommendations made by [26] and the conditions of the present work. For the major species, the uncertainty of the mole fractions is estimated as $20 \%$, increasing to $30 \%$ at heights below the reaction zone. For stable minor species with measured PICSs, the uncertainty is within $70 \%$; but for radicals or species with estimated PICSs, the factor can be as large as 2-3. In Table S3, we list the peak mole fractions of all minor species together with their uncertainty factors.

All species mole fraction profiles in both the pyrolysis and premixed flame experiments are given in the Supplemental material.

\section{Kinetic modeling}


In this work, simulation of premixed flames, pyrolysis, opposed-flow diffusion flames, ignition delay times and flame speeds for DMC were performed using the Chemkin Pro software [38]. The kinetic model is composed of the DMC sub-mechanism and the core $\mathrm{C}_{0}-\mathrm{C}_{4}$ mechanism. The DMC sub-mechanism includes 23 reactions, as listed in Table 2 with the corresponding Arrhenius parameters; only values at 1 atm are listed; detailed information about the pressure dependence is given in Table S4. Rate coefficients for some key reactions were evaluated as described below, addressing several reaction classes.

\subsection{Unimolecular reactions}

Unimolecular reactions are essential under pyrolysis conditions, although they have not been adequately accounted for in previous models. The rate coefficient of the $\mathrm{CO}_{2}$ elimination reaction (R1) was estimated in the Glaude model [11] by combining calculation and analogy to isomerization of the 2-methylhexyl radical [42], and it was not modified in the Hu model [15]. Furthermore, in the Glaude model [11], the rate coefficients for R2 and R6 were considered equal as both sets of parameters were obtained through analogy with the decomposition reaction of DME. Only one type of the C-O bond exists in the structure of DME while the DMC molecule features two types of C-O bonds with quite different bond dissociation energies (BDEs), see Fig. 2. Therefore, it is not appropriate to assign the same rate constant to R2 and R6. In the Hu model [15], these rate coefficients were directly taken from methyl butanoate reactions, which also could lead to substantial uncertainties. As a result, we have re-examined all of the DMC unimolecular decomposition reaction rates.

Peukert et al. [12, 13] provided a high-level potential energy surface (PES) for DMC decomposition at the $\operatorname{CCSD}(\mathrm{T}) / \mathrm{cc}-\mathrm{pv} \infty \mathrm{Z} / / \mathrm{M} 06-2 \mathrm{X} / \mathrm{cc}-\mathrm{pvtz}$ level. The pressure- dependent rate coefficients were determined based on the computed PES using the VARIFLEX code [43], while isomerization between various conformers was neglected in the master equation simulation. We re-computed the rate coefficients from 0.04 atm to $1000 \mathrm{~atm}$ in the temperature range of 500-2300 $\mathrm{K}$ using a newly developed master equation code - PAPER [44]. In these calculations, different from the original work, the isomerization of the cis-cis and cis-trans conformers of DMC was taken into account. The PES as well as the resulting rate coefficients used in our kinetic calculations are shown in Fig. S2 and Table S4 in the Supplemental material. The barrierless decomposition channels were treated by the Phase Space Theory. The energy transfer parameters used in the work of Peukert et al. [12] were also adopted in our calculations. The vibrational modes corresponding to the internal rotations were approximated as 1-D hindered rotors, while the hindrance potential was calculated at M06-2X/cc-pvtz. Quantum tunneling effects were also included using the asymmetric Eckart tunneling model. 


\subsection{Hydrogen abstraction reactions}

Hydrogen abstraction reactions are one of the key pathways in fuel destruction and oxidation. We have adopted the rate coefficients of $\mathrm{H}$-atom abstractions from DMC by $\mathrm{H}$ and $\mathrm{O}$ (R7 and R8) from Peukert et al. [12]. For other reactions of this category (R9-R18) without calculated rate coefficients, reasonable analogies have been postulated. Glaude et al. [11] have roughly estimated the rate coefficients of $\mathrm{H}$-atom abstraction reactions via analogies to alkanes, while analogies to methyl butanoate were adopted in the Hu model [15].We suggest different analogies which we consider more reasonable in constructing our model, as explained below.

As shown in Fig. 2, methyl formate and DMC share substantial similarities in their structures: the $\mathrm{C}-\mathrm{C}$ bond is absent from both compounds while the BDEs of the primary $\mathrm{C}-\mathrm{H}$ bonds for abstraction (101.1 and $100.9 \mathrm{kcal} / \mathrm{mol}$ ) are similar, and the BDEs of $\mathrm{C}-\mathrm{O}$ bonds in the methoxy group are close $(89.6$ and $90.1 \mathrm{kcal} / \mathrm{mol})[11,39]$.

Therefore we consider the analogy to methyl formate more meaningful, especially because the chemical surrounding of the $\mathrm{C}-\mathrm{H}$ bond may also affect the rate coefficients of the $\mathrm{H}$-atom abstraction reactions. Consequently we have estimated the rate coefficients based on a widely validated detailed kinetic model of methyl formate by Dooley et al.[39]. These authors have correlated the rate coefficient for each reaction with the BDEs for an $\mathrm{H}$-atom from extensively reviewed literature data on $\mathrm{H}$-atom abstraction for a number of similar fuels. The Arrhenius parameters used in our model were taken from the corresponding reactions in Dooley's methyl formate model, with some necessary corrections, however. Specifically, pre-exponential factors were multiplied by two because there the $\mathrm{H}$ atoms available for abstraction in the methyl groups of a DMC molecule are twice that of the single methyl group in methyl formate. Furthermore, considering the radical pool of the DMC reactions, abstractions by 10 radicals or molecules in addition to $\mathrm{H}$ and $\mathrm{O}$ atoms (R9-R18) were included.

\subsection{Radical decomposition and recombination}

Fuel breakdown and oxidation mechanisms involve delicate balances of radical reactions. As primary radicals in the fuel decomposition pathways, $\mathrm{CH}_{3} \mathrm{OC}(=\mathrm{O}) \mathrm{OCH}_{2}$ and $\mathrm{CH}_{3} \mathrm{OC}(=\mathrm{O}) \mathrm{O}$ radicals can be formed via hydrogen abstraction (R7-R18) or bond dissociation (R2). These fuel-related radicals break down via the low-energy-barrier $\beta$-scission. Rate coefficients for these reactions (R19 and R20) were calculated with the same method as employed for the DMC unimolecular system, and the high pressure limits were presented in the mechanism.

The branching decomposition of the $\mathrm{CH}_{3} \mathrm{OCO}$ radical leading to $\mathrm{CO}_{2}$ or $\mathrm{CO}$ formation (R21 and R22) is ubiquitous in the DMC chemistry. The significance of this pair of competing reactions was pointed out by Glaude et al. [11] who stated that their branching ratio could represent the 
efficiency of the oxygen atom usage. However, they calculated their rate coefficients at high

pressure limits without considering the pressure dependence. The fate of the $\mathrm{CH}_{3} \mathrm{OCO}$ radical was also investigated in several theoretical and modeling studies [40, 45, 46] related to methyl esters as it is of essence in the combustion chemistry of methyl esters. Violi et al. [46] determined the high-pressure limits of the branching reactions in their shock tube study of methyl butanoate, with results close to those of Glaude et al. [11], and Farooq et al. [47] found that the branching ratio of $\mathrm{CH}_{3} \mathrm{OCO}$ consumption in Reactions $\mathrm{R} 21$ and $\mathrm{R} 22$ controlled the ratio of $\mathrm{CO} / \mathrm{CO}_{2}$ production in shock tube pyrolysis of methyl propanoate pyrolysis behind reflected shock waves. In a recent experimental and modeling study of methyl propanoate pyrolysis at low pressure, Zhao et al. [40] calculated the rate coefficients of the branching pair at different pressures ranging from 0.0066 atm to $10 \mathrm{~atm}$. Their values were adopted in the present work since we intend to construct a detailed kinetic model covering a wide range of pressures. However, since the calculation was performed in the temperature range of 500 to $1500 \mathrm{~K}$, it needs to be confirmed that the extrapolation to higher temperatures is reasonable. Regarding the importance of the branching reactions of the $\mathrm{CH}_{3} \mathrm{OCO}$ radical, further theoretical and experimental works should be devoted to the decomposition of $\mathrm{CH}_{3} \mathrm{OCO}$ in a broader range of temperatures and pressures.

A recombination reaction of $\mathrm{CH}_{3}$ and fuel radical $\left[\mathrm{CH}_{3} \mathrm{OC}(=\mathrm{O}) \mathrm{OCH}_{2}\right](\mathrm{R} 23)$ with an estimated rate coefficient was also included in the model. Radical recombination reactions of this type are considered important in low-pressure flame conditions, but they have generally not been well studied [48]. Similar reactions were considered in building the mechanisms of small esters [39, 41], where they could contribute to the formation of $\mathrm{C}_{2}$ hydrocarbon intermediates in those flames.

As a core $\mathrm{C}_{0}-\mathrm{C}_{4}$ mechanism, we have chosen the Aramco Mech 1.3 proposed by Curran et al. [49] for several reasons. This core mechanism was extensively validated with different fuels under a wide range of experimental conditions. More importantly, it includes a detailed sub-mechanism of DME, which is a key intermediate of the DMC chemistry. In fact, after comparing the performance of several core mechanisms [49-51], we found that the predictions for most hydrocarbon species are independent of the choice of the core mechanism. However, Aramco Mech 1.3 [49] showed some advantages in predicting the oxygenated species mole fractions, which are important in the DMC chemistry. The group additivity method was utilized to calculate the thermochemical parameters with the program THERM [52] for DMC related species and the used groups and their values are presented in Table S5. Thermochemical data of other species and the transport parameters were taken from Aramco Mech 1.3 [49] and the Glaude model [11]. We have ensured the consistency of thermochemical properties and transport data of species before we merged the $\mathrm{C}_{0}-\mathrm{C}_{4}$ core mechanism and the DMC sub-mechanism. 
The entire mechanism consists of 257 species and 1563 reactions, which are given in the Supplemental material as the kinetic, thermochemical and transport files.

\section{Results and discussion}

The performance of the kinetic model was examined with all available experimental results from this study and from the literature (see also Table 1) including various conditions. Sensitivity and reaction paths analyses were then conducted with this model to interpret the chemical details for DMC combustion and to provide further guidance for experiments and model development. The discussion is given in several parts, corresponding to different experiments. The emphasis is placed on the investigations of pyrolysis and laminar premixed flames from this work. These studies, as well as opposed-flow diffusion flame results from the literature, convey detailed chemical composition information. Insights into certain species can facilitate an overview of the reaction network and the optimization of kinetic parameters of the crucial reaction sequences. Therefore, laminar burning velocities and ignition delay times from the literature, both global combustion properties of DMC, are also examined since they are expected to be well captured by a predictive model.

\subsection{DMC pyrolysis in a flow reactor}

The pyrolysis experiments of the present work were simulated with the Plug Flow Code of the Chemkin Pro program [38], which has been demonstrated to simulate well such experiments [53, 54]. When the PFR model is employed, the basic assumption that the axial diffusion of any quantity is negligible relative to the corresponding convective term should be satisfied. For the pyrolysis mixture in the flow tube, the non-dimensional Péclet number $(\mathrm{Pe})$, which is the rate of advection of a physical quantity by the flow to the rate of diffusion of the same quantity driven by an appropriate gradient, was checked to be large enough so that axial diffusion could be ignored. The measured temperature profile corresponding to each $T_{\max }$ was taken as input under all experimental conditions to calculate the mole fraction profile for each species along the flow reactor. Since the species mole fractions were measured only at the outlet of the flow tube, the simulated value at this position was used to compare experimental and simulated results.

Comparisons between measured and modeled mole fraction profiles for DMC, main products $\left(\mathrm{CO}_{2}, \mathrm{CO}\right.$ and DME) and selected minor species are given in Figs. 3 4. Predictions with the Glaude model [11] and Hu model [15] are also included. It is seen that, compared to previous models, the present model yields much improved prediction of the mole fraction profiles of the major species, though profiles of the minor species including the $\mathrm{C}_{1} \sim \mathrm{C}_{2}$ hydrocarbons can also be well reproduced by the Hu model. This result is to be expected since the previous models were never tested under 
pyrolysis conditions even though the main decomposition pathways were included, suggesting that the corresponding kinetic parameters might not be correct.

Based on the rate of production (ROP) analysis of some specific species, a reaction network was established in Fig. 5 to illustrate the main paths for the DMC decomposition. For the DMC pyrolysis under 40, 200 and 1040 mbar, a ROP analysis was performed for $T_{\max }$ of 1337, 1233 and $1122 \mathrm{~K}$, respectively, where approximately half of the fuel was consumed. In such conditions, the fuel decomposes at a fast pace with most dissociation channels contributing notably to its consumption. As shown in Fig. 5, the four reactions, R1 $\left(\mathrm{COC} * \mathrm{OOC}=\mathrm{CH}_{3} \mathrm{OCH}_{3}+\mathrm{CO}_{2}\right), \mathrm{R} 2$ $\left(\mathrm{COC}^{*} \mathrm{OOC}=\mathrm{COC}^{*} \mathrm{OO}+\mathrm{CH}_{3}\right), \mathrm{R} 7\left(\mathrm{COC}^{*} \mathrm{OOC}+\mathrm{H}=\mathrm{COC} * \mathrm{OOCj}+\mathrm{H}_{2}\right)$ and $\mathrm{R} 11\left(\mathrm{COC}^{*} \mathrm{OOC}+\right.$ $\left.\mathrm{CH}_{3}=\mathrm{COC} * \mathrm{OOCj}+\mathrm{CH}_{4}\right)$, contribute more than $99 \%$ in the initial steps for the DMC decomposition. With increasing pressure, bimolecular reactions (R7 and R11) contribute more to the fuel depletion whereas the contribution from unimolecular reactions (R1 and R2) decreases. Nevertheless, R1 remains the dominant DMC consumption pathway in all cases, directly leading to the formation of dimethyl ether $\left(\mathrm{CH}_{3} \mathrm{OCH}_{3}, \mathrm{DME}\right)$ and $\mathrm{CO}_{2}$. This crucial pathway could also explain the abundant presence of DME, as shown in Fig. 3 (c), which is, however, slightly over-predicted.

Figure 6 shows that R1 and R2 have the largest sensitivity coefficients regarding for the decomposition of DMC. The sensitivity of R1 is to be expected because it contributes the most to fuel consumption. As for R2, it is not only one of the major DMC consumers, but it also simultaneously produces the methyl $\left(\mathrm{CH}_{3}\right)$ and $\mathrm{CH}_{3} \mathrm{OC}(=\mathrm{O}) \mathrm{O}$ radicals, and leads to further steps in the decomposition of $\mathrm{CH}_{3} \mathrm{OC}(=\mathrm{O}) \mathrm{O}$ radical that yields the $\mathrm{H}$-atom. The $\mathrm{H}$-atom and $\mathrm{CH}_{3}$ radical will then attack the $\mathrm{DMC}$ molecule through $\mathrm{R} 7$ and $\mathrm{R} 11$, respectively, thus accelerating the consumption of DMC. As stated above, we have re-calculated the pressure-dependent rate coefficients for R1 and R2 based on the high-level PES provided by Peukert et al. [12, 13] with two conformers of DMC taken into consideration. In the work of both Glaude et al.[11] and Hu et al.[15], the rate coefficients for these two reactions were estimated through rough calculation or analogies, while only the high pressure limits were given in Glaude et al. [11]. The rate coefficients of R1 and R2 (denoted as $k_{1}$ and $k_{2}$ ) from different works are compared in Fig. S3 at the $1 \mathrm{~atm}$ pressure.

Our calculations for $k_{1}$ and $k_{2}$ are not significantly different from those of Peukert et al. [12, 13]. However, R1 and R2 are two channels that compete with each other for the DMC unimolecular decomposition, as shown in the PES of Fig. S2. Therefore their branching ratio is supposed to have a more pronounced effect than the rate coefficients themselves, as demonstrated in Fig. 7. The $k_{1} / k_{2}$ ratio of the present work is about two orders of magnitudes lower than that of Peukert et al.[12] at 
the atmospheric pressure in the temperature range studied here. The present calculations, including

an assumed uncertainty of a factor of two in the calculations of $k_{1}$ and $k_{2}$ (indicated as the shadowed areas) are in excellent agreement with the measured values. If the calculated values by Peukert et al. $[12,13]$ were adopted, however, the predicted consumption of DMC would be much earlier and faster than observed in the experiment, clearly outside of the shadowed area.

In the thermal decomposition of $\mathrm{DMC}, \mathrm{CO}$ is produced after $\mathrm{CO}_{2}$ (compare Fig. 3), which is quite different from the pyrolysis processes of other oxygenates such as ethers and alcohols [53, 55, 56]. Furthermore, Fig. 5 shows that several fuel-related reactions contribute to $\mathrm{CO}_{2}$ formation whereas nearly all CO is produced through reactions of small molecules. The early formation and relatively high concentrations of $\mathrm{CO}_{2}$ have also been observed in previous studies of the methyl ester combustion chemistry $[29,34,46,57]$. Such phenomena were explained by the presence of the $\mathrm{CH}_{3} \mathrm{OCO}$ radical in which fission of the $\mathrm{CH}_{3}-\mathrm{O}$ bond can directly lead to $\mathrm{CO}_{2}$ formation (R21). The $\mathrm{CH}_{3} \mathrm{OCO}$ radical is also abundant in the DMC chemistry as a product of the energy-favored $\beta$-scission of the fuel radical $\mathrm{CH}_{3} \mathrm{OC}(=\mathrm{O}) \mathrm{OCH}_{2}$ (R19) following hydrogen abstractions.

To further investigate the formation of $\mathrm{CO}_{2}$, an $\mathrm{ROP}$ analysis for $\mathrm{CO}_{2}$ at 40 mbar are shown in Fig. 8, with $T_{\max }$ ranging from $1093 \mathrm{~K}$ (at which $\mathrm{CO}_{2}$ begins to be produced) to $1490 \mathrm{~K}$. According to Fig. 8, the three reactions, R1, R20 and R21, together take up more than $99 \%$ of the $\mathrm{CO}_{2}$ production. $\mathrm{R} 21$ is one of the major $\mathrm{CO}_{2}$ contributors as expected. The contribution from $\mathrm{R} 1$ is dominant as this molecular elimination reaction with a four-centered transition state has a relatively low energy barrier. $\mathrm{R} 20$ is the $\beta$-scission product of the $\mathrm{CH}_{3} \mathrm{OC}(=\mathrm{O}) \mathrm{O}$ radical obtained via the bond fission of DMC (R2). With increasing temperature, the contribution from R1 decreases while R20 becomes increasingly important. The easier occurrence of R2 at higher temperatures, constituting direct bond decomposition, accounts for such trends. This is corroborated from an inspection of Fig. $\mathbf{S 3}$ which shows that, at the same pressure, in a lower temperature range, $k_{1}$ is greater than $k_{2}$, but at higher temperatures, $k_{2}$ becomes comparable to or even larger than $k_{1}$.

Some hydrocarbon intermediates including $\mathrm{CH}_{4}, \mathrm{C}_{2} \mathrm{H}_{6}, \mathrm{C}_{2} \mathrm{H}_{4}$ and $\mathrm{C}_{2} \mathrm{H}_{2}$ were detected and quantified, as shown before in Fig. 4. It is noted that the present model can precisely predict the mole fraction variations, and the order of appearance of the $\mathrm{C}_{2}$ species is in line with the ROP-analyzed reaction path of $\mathrm{CH}_{3} \rightarrow \mathrm{C}_{2} \mathrm{H}_{6} \rightarrow \mathrm{C}_{2} \mathrm{H}_{4} \rightarrow \mathrm{C}_{2} \mathrm{H}_{2}$ indicated in Fig. 5. Furthermore, $\mathrm{C}_{2} \mathrm{H}_{5}$ from the radical recombination reaction $\mathrm{R} 23$ is negligible. $\mathrm{C}_{3}$ and larger hydrocarbon species are below the detection limit of $1 \mathrm{ppm}$ in our experiment, which indicates that larger hydrocarbons are hard to form during the DMC pyrolysis due to the absence of $\mathrm{C}-\mathrm{C}$ bonds in the DMC molecule.

Recognizing that unimolecular reactions are sensitive and important under pyrolysis conditions, the good agreement between the present experimental and modeling results suggests the viability of 
the kinetic parameters of these reactions in the present model. Next, the chemical structures of

low-pressure premixed laminar flames, which require kinetic features dealing with oxidation as well as pyrolysis, will provide further information on the high-temperature combustion chemistry of DMC.

\subsection{Low-pressure laminar premixed DMC flames}

Species identification is the first step in the mole fraction measurement in premixed flame studies, especially those fueled by oxygenates, where several possible species (hydrocarbons or oxygenates) usually correspond to the same mass number. In this work, the high-resolution mass spectrometry together with the PIE measurements [21] ensured distinct identification of each flame species. The mass resolution is illustrated in Fig. S4 in the Supplemental material. In total, 29 species were identified and quantified in each flame. This includes methyl formate $\left(\mathrm{CH}_{3} \mathrm{OCHO}\right.$, $m / z=60$ ) which was not detected in a DMC-doped heptane flame [6], but could be unambiguously identified in the present study from the comparison of the PIE spectrum with the photoionization cross section of methyl formate [36], as shown in Fig. S5. Also, $C_{3}$ species were detected in the flames at the 1-50 ppm level, which were below the detection limit under pyrolysis conditions.

The kinetic modeling calculations reported in this section were performed using the Premixed code of Chemkin Pro software [38]. The experimentally determined temperature profiles were taken as input parameters. Multi-component transport and thermal diffusion were considered in the calculations. Gradient and curvature tolerances were set as 0.1 and 0.05 , respectively, producing converged, grid-independent solution with up to 300 grid points.

Figures 9 11 compare of the experimental results with the model calculations. Because of the higher measurement error within $1 \mathrm{~mm}$ from the burner surface (see Section 2.3), the related data are shown in lighter color. Figure 9 shows the temperature profiles and mole fractions of the major species $\left(\mathrm{CO}_{2}, \mathrm{CO}, \mathrm{H}_{2} \mathrm{O}, \mathrm{H}_{2}, \mathrm{Ar}, \mathrm{DMC}\right)$ for the two different equivalence ratios. The modeling results agree well with the experimental values within the experimental uncertainty. The flame structure in both cases was also reproduced with the Glaude model [11] and Hu model [15], both of which can satisfactorily predict profiles of the major species; their modeling results are not presented here to avoid cluttering.

Good agreement of the major species mole fraction profiles however cannot guarantee a predictive kinetic model. Additional scrutiny is needed on the minor hydrocarbon and oxygenated intermediates, shown in Figs. 10 11, respectively. Generally, the present model offers better reproduction of the measured mole fraction profiles for most intermediates than previous models, particularly the $\mathrm{C}_{3}$ and oxygenated species. It is noted, however, that the experimental uncertainty factors for different species are different and can be large, as listed in Table S3. As evident from 
Figs. 10 11 as well as Table S3, most intermediates show later peak positions in the fuel-rich

flame because it has a larger flame thickness than the stoichiometric flame; while the higher peak mole fractions of intermediates in the fuel-rich flame might be partly due to the higher initial fuel concentration, $25 \%$ in the fuel-rich flame and $18.75 \%$ in the stoichiometric flame, as indicated in Table 1.

It is of interest to pursue the formation of intermediates along the reaction path from the fuel towards smaller hydrocarbon and oxygenated species in these low-pressure flames, as provided from the integrated ROP analysis along the entire flame in Fig. 12, and also compare with those under pyrolysis conditions given in Fig. 5. As discussed for the pyrolysis experiment, hydrogen abstraction leading to the $\mathrm{CH}_{3} \mathrm{OC}(=\mathrm{O}) \mathrm{OCH}_{2}$ radical as well as unimolecular reactions play a role; in the flames, however, the former reaction consumes most of the fuel. The fuel radical $\mathrm{CH}_{3} \mathrm{OC}(=\mathrm{O}) \mathrm{OCH}_{2}$ is ubiquitous in the flame mixtures but is too reactive to be detected and it subsequently leads to the formation of formaldehyde $\left(\mathrm{CH}_{2} \mathrm{O}\right)$ through a low-energy-barrier $\beta$-scission reaction (R19), which results in the largest concentration of $\mathrm{CH}_{2} \mathrm{O}$ among all intermediates in both flames. According to the ROP analysis in Fig. S6, reaction (R19) contributes almost half of the $\mathrm{CH}_{2} \mathrm{O}$ formation in both flames, while several reactions of small species are also involved.

As shown in Fig. 9, $\mathrm{CO}_{2}$ and $\mathrm{CO}$ are produced in these DMC flames at similar rates. This behavior is quite different from the conventional laminar low-pressure flame structure for hydrocarbon fuels, where large quantities of hydrogen $\left(\mathrm{H}_{2}\right)$, carbon monoxide $(\mathrm{CO})$ and water $\left(\mathrm{H}_{2} \mathrm{O}\right)$ are produced rapidly in the reaction zone, and the conversion of $\mathrm{CO}$ to carbon dioxide $\left(\mathrm{CO}_{2}\right)$ occurs farther downstream. The reaction paths presented in Fig. 12 suggest the early formation of $\mathrm{CO}_{2}$. Besides $\mathrm{CH}_{2} \mathrm{O}$, the decomposition of $\mathrm{CH}_{3} \mathrm{OC}(=\mathrm{O}) \mathrm{OCH}_{2}$ radical also yields abundant $\mathrm{CH}_{3} \mathrm{OCO}$ radical, over $90 \%$ of which break down into $\mathrm{CO}_{2}$ and $\mathrm{CH}_{3}(\mathrm{R} 21)$. In addition, the $\mathrm{CH}_{3} \mathrm{OC}(=\mathrm{O}) \mathrm{O}$ radicals formed from the direct bond fission of the fuel are completely converted to $\mathrm{CO}_{2}$ and the $\mathrm{CH}_{3} \mathrm{O}$ radicals (R20). Moreover, the molecular elimination of $\mathrm{CO}_{2}$ from DMC (R1) contributes to the $\mathrm{CO}_{2}$ formation. These three fuel-related reactions, together with the reaction $\mathrm{CO}+\mathrm{OH}=\mathrm{CO}_{2}+\mathrm{H}$, explain almost the complete $\mathrm{CO}_{2}$ formation. An ROP analysis for $\mathrm{CO}_{2}$ was performed along the distance from the burner, as shown in Fig. 13. The results indicate that the steep rise of the $\mathrm{CO}_{2}$ mole fraction near the burner results from the prevailing significance of fuel-related reactions in this region. This is similar to the conditions in the pyrolysis experiments, because pyrolysis occurs in the early stage of combustion as mentioned previously. Among these fuel-related reactions, the decomposition of the $\mathrm{CH}_{3} \mathrm{OCO}$ radical (R21) contributes the most, because $\mathrm{H}$ - abstraction dominates fuel consumption due to the abundance of radicals under these flame conditions. Further 
away from the burner, the oxidation of $\mathrm{CO}$ by $\mathrm{OH}\left(\mathrm{CO}+\mathrm{OH}=\mathrm{CO}_{2}+\mathrm{H}\right)$ becomes dominant. That the

contribution of this reaction being more prominent in the stoichiometric flame, is largely a consequence of the higher concentration of the $\mathrm{OH}$ radical under such conditions.

As shown in Fig. 11(e), $\mathrm{CH}_{3} \mathrm{OCHO}$ was detected in both flames, with the non-negligible level of $10^{-4}$, due to the abundance of the $\mathrm{CH}_{3} \mathrm{OCO}$ radical. Only less than $2 \%$ of the $\mathrm{CH}_{3} \mathrm{OCO}$ radicals combine with the $\mathrm{H}$ atom $\left[\mathrm{CH}_{3} \mathrm{OCO}+\mathrm{H}=\mathrm{CH}_{3} \mathrm{OCHO}\right.$ (not shown in Fig. 12)], but lead to nearly all of the $\mathrm{CH}_{3} \mathrm{OCHO}$ formation. Dimethyl ether (DME) as a crucial intermediate in DMC flames attains peak mole fractions exceeding $10^{-3}$, as shown in Fig. 11(d). All the DME comes from the molecular elimination of DMC (R1), which is similar to the pyrolysis case. According to the reaction paths shown in Fig. 12, DME mainly breaks down through $\mathrm{H}$-abstraction and the subsequent $\beta$-scission, ending up in $\mathrm{CH}_{3}$ and $\mathrm{CH}_{2} \mathrm{O}$.

As shown in Fig. 10(a), $\mathrm{CH}_{3}$ has remarkable concentrations in both flames. The simulated peak mole fractions are higher than the measured ones, which may be due to a potential loss of the reactive radicals on the sampling cone. Figure 11 shows that $\mathrm{CH}_{3}$ is involved in numerous reactions. Apart from being oxidized by the $\mathrm{O}, \mathrm{OH}$ and $\mathrm{HO}_{2}$ radicals, it can combine with the $\mathrm{H}$-atom or itself, producing $\mathrm{CH}_{4}$ and $\mathrm{C}_{2} \mathrm{H}_{6}$, respectively. In spite of the absence of $\mathrm{C}-\mathrm{C}$ bonds in the fuel molecule, both experiments and simulations show the existence of $\mathrm{C}_{2}$ species such as ethane $\left(\mathrm{C}_{2} \mathrm{H}_{6}\right)$, ethylene $\left(\mathrm{C}_{2} \mathrm{H}_{4}\right)$ and acetylene $\left(\mathrm{C}_{2} \mathrm{H}_{2}\right)$; of $\mathrm{C}_{3}$ species such as propargyl $\left(\mathrm{C}_{3} \mathrm{H}_{3}\right)$, propyne $\left(\mathrm{C}_{3} \mathrm{H}_{4}\right.$-p), allene $\left(\mathrm{C}_{3} \mathrm{H}_{4}-\mathrm{a}\right)$ and propene $\left(\mathrm{C}_{3} \mathrm{H}_{6}\right)$, and even of $\mathrm{C}_{4}$ species (see Table 2). ROP analysis for the $\mathrm{C}_{2}$ species suggests that their formation follows the main dehydrogenation pathway of $\mathrm{C}_{2} \mathrm{H}_{6} \rightarrow \mathrm{C}_{2} \mathrm{H}_{5} \rightarrow \mathrm{C}_{2} \mathrm{H}_{4} \rightarrow \mathrm{C}_{2} \mathrm{H}_{3} \rightarrow \mathrm{C}_{2} \mathrm{H}_{2}$. Even though the recombination of the fuel radical and $\mathrm{CH}_{3}$ is taken into consideration, the contribution of this reaction to $\mathrm{C}_{2} \mathrm{H}_{5}$ formation is negligible. The mole fraction for $\mathrm{C}_{2} \mathrm{H}_{4}$ and $\mathrm{C}_{2} \mathrm{H}_{2}$ are under-estimated by the present model and such discrepancy between computed and measured for unsaturated $\mathrm{C}_{2}$ species was also found in similar flame studies of small esters $[33,34,58]$. Considering the over-prediction of $\mathrm{C}_{2} \mathrm{H}_{6}$, the current rate for $\mathrm{C}_{2} \mathrm{H}_{6}$ degeneration path might be too slow. The possible problem with small molecules is beyond the scope of the present study focusing on chemical characteristics of DMC.

It should be noted that the peak mole fractions of $\mathrm{C}_{3}$ species in DMC flames can be more than one order of magnitude lower than those in propane flames [23] with similar equivalence ratios; and they are also notably lower than those in the $\mathrm{C}_{3}$ ester (methyl acetate and ethyl formate) flames [29]. ROP analysis suggests that $\mathrm{C}_{3} \mathrm{H}_{3}$ is formed from the $\mathrm{C}_{3} \mathrm{H}_{4}$ species, which are converted from $\mathrm{C}_{3} \mathrm{H}_{6}$ and related species formed through the $\mathrm{C}_{1}+\mathrm{C}_{2}$ reactions. The pathways are in accordance with the appearance sequence of the peak positions of these $\mathrm{C}_{3}$ species presented in Fig. 10. The $\mathrm{C}_{4}$ species in DMC flames (not shown in Figs. 10 11) are of relatively low concentrations, which mainly come 
from the recombination reactions of $\mathrm{C}_{2}+\mathrm{C}_{2}$ and $\mathrm{C}_{1}+\mathrm{C}_{3}$. It is noted that benzene $\left(\mathrm{C}_{6} \mathrm{H}_{6}\right)$, typically considered as the first aromatic ring in soot-formation processes, is below our detection limit (1 $\mathrm{ppm}$ ), which is consistent with the relatively low concentrations of the $\mathrm{C}_{3}$ species $[59,60]$.

Two further oxygenated intermediates typical for the combustion of oxygenated fuels are acetaldehyde $\left(\mathrm{CH}_{3} \mathrm{CHO}\right)$ and ketene $\left(\mathrm{CH}_{2} \mathrm{CO}\right)$, the profiles of which are also shown in Fig. 11. Neither species is formed directly in the fuel decomposition paths and as such are not involved in the reaction network shown in Fig. 12. ROP analyses were performed for both species and are given in Fig. S7(a) for acetaldehyde and Fig. S7(b) for ketene. In short, acetaldehyde is mainly formed from reactions involving the $\mathrm{C}_{2}$ species. It can isomerize to ethenol $\left(\mathrm{C}_{2} \mathrm{H}_{3} \mathrm{OH}\right)$, as confirmed by the detection of $\mathrm{C}_{2} \mathrm{H}_{3} \mathrm{OH}$ in the present study (see Table 2). The formation reactions for $\mathrm{CH}_{2} \mathrm{CO}$ are interesting regarding the absence of $\mathrm{C}-\mathrm{C}$ bonds in the DMC molecule. Therefore, in spite of the similarities noted with the combustion of small methyl esters such as the immediate formation of $\mathrm{CH}_{2} \mathrm{O}$ after $\mathrm{H}$-atom abstraction from the methyl group [43, 61], the respective ketene formation pathways are unlikely. For example, for the $\mathrm{C}_{3}$ methyl ester methyl acetate $\left[\mathrm{CH}_{3} \mathrm{C}(=\mathrm{O}) \mathrm{OCH}_{3}\right]$, a molecular elimination can occur through a four-member cyclic transition state, yielding ketene $\left(\mathrm{CH}_{2} \mathrm{CO}\right)$ [61] and methanol $\left(\mathrm{CH}_{3} \mathrm{OH}\right)$. Furthermore, the methyl acetate fuel radical $\mathrm{CH}_{2} \mathrm{C}(=\mathrm{O}) \mathrm{OCH}_{3}$ can break down through $\beta$-scission, simultaneously producing $\mathrm{CH}_{2} \mathrm{CO}$ and $\mathrm{CH}_{3} \mathrm{O}$. Considering the absence of $\mathrm{C}-\mathrm{C}$ bonds in DMC, these categories of reactions cannot occur. We observed $\mathrm{CH}_{2} \mathrm{CO}$ in our experiments with relatively low mole fractions of the order of $10^{-5}$. ROP analysis of $\mathrm{CH}_{2} \mathrm{CO}$ in Fig. S7(b) suggests that only small species reactions are involved in the $\mathrm{CH}_{2} \mathrm{CO}$ formation and consumption.

The above results demonstrate that the performance of the present model is satisfactory in reproducing the premixed flame measurements of this work.

\subsection{Opposed flow diffusion flame of DMC}

As an additional scrutiny, the present model was examined against the results of Sinha and Thomson [10] who investigated the chemical structure of a DMC opposed flow diffusion flame under atmospheric pressure. The oxidizer stream was composed of $61 \% \mathrm{~N}_{2}$ and $39 \% \mathrm{O}_{2}$, while the fuel stream consisted of $92 \% \mathrm{~N}_{2}$ and $8 \%$ DMC. Eight stable species were quantitatively detected with GC and HPLC. Both the Glaude model [11] and Hu model [15] reproduced the experimental results well. Here, the OPPDIF code within the Chemkin Program [38] was used to model the opposed flow diffusion flame structure, with mixture-averaged transport and thermal diffusion. The number of grid points was 30 . Figure 14 shows that the simulation agrees reasonably well with the experimental profiles. Some deviations are noted in the profile shapes of the intermediates, especially for $\mathrm{CH}_{2} \mathrm{O}$, while peak values are typically reproduced within a factor of two (for $\mathrm{CH}_{4}$ ) or 
better. These differences are likely to be minor regarding the experimental uncertainties.

At this point, results of the detailed kinetic model have been compared with all available measured species fraction profiles. Nevertheless, a good capture of global combustion parameters is a prerequisite for a practical kinetic model which should exhibit predictive capacity. Hu et al. [15] and Bardin et al.[14] have measured ignition delay times and burning velocities of DMC respectively, which will be used to further scrutinize our model.

\subsection{Global DMC combustion behavior: Ignition delay time and laminar burning velocity}

In a shock tube study [15], ignition delay times of DMC were measured at $T=1100 \mathrm{~K}-1600 \mathrm{~K}$, $p=0.12-1.0 \mathrm{MPa}$, fuel concentration $=0.5 \%-2 \%$ and $\phi=0.5-2.0$. The time interval between the arrival of the incident shock wave at the end wall and the intercept of the maximum slope of the measured $\mathrm{CH}^{*}$ trajectory with the zero line was defined as the measured ignition delay time. By running the Senkin code of the Chemkin Pro program [38] with the newly developed model, we calculated ignition delay times under these experimental conditions. The present model predicts these ignition delay times well, having a significant advantage over the Glaude model [11], as seen in Fig. 15. The simulations with the Hu model [15] which can well reproduce their own measurements are not presented in Fig. 15 to avoid cluttering. A sensitivity analysis was performed at $T=1350 \mathrm{~K}, p=0.12 \mathrm{MPa}$ and $\phi=1.0$, at the same conditions as that reported by $\mathrm{Hu}$ et al. [15]; the results are shown in Fig. S9. Consistent with the work of $\mathrm{Hu}$ et al. [15], the chain branching reaction $\mathrm{H}+\mathrm{O}_{2}=\mathrm{O}+\mathrm{OH}$ dominates the ignition chemistry, and the fuel decomposition reaction (R2) has the second largest negative sensitivity coefficient. The reaction with the largest positive sensitivities in Fig. S9 are the $\mathrm{H}$-abstractions from DME and DMC by $\mathrm{H}$-atoms to produce $\mathrm{H}_{2}$, $\mathrm{CH}_{3} \mathrm{OCH}_{3}+\mathrm{H}=\mathrm{CH}_{3} \mathrm{OCH}_{2}+\mathrm{H}_{2}$ and (R7), respectively. Both reactions slow the rate of ignition (i.e., increase the ignition delay time) because they compete with R1 for the H-atoms. Every $\mathrm{H}$-atom that reacts with DME or DMC therefore cannot react with $\mathrm{O}_{2}$ via the reaction of $\left(\mathrm{H}+\mathrm{O}_{2}=\mathrm{O}+\mathrm{OH}\right)$ to provide vigorous chain branching, causing an inhibition effect instead. DME is exclusively formed from the molecular elimination reaction (R1) which plays an important role in the DMC ignition. It is noted that both $\mathrm{R} 1$ and the reaction $\mathrm{CH}_{3} \mathrm{OCH}_{3}+\mathrm{H}=\mathrm{CH}_{3} \mathrm{OCH}_{2}+\mathrm{H}_{2}$ are not included in the analysis of $\mathrm{Hu}$ et al. [15] as the significance of $\mathrm{R} 1$ and related species and reactions was under-estimated in their model.

The laminar burning velocity $\left(S_{L}\right)$ of DMC/air flames was determined by Bardin et al. [14] as a function of the equivalence ratio at initial gas mixture temperatures of 298, 318, 338 and $358 \mathrm{~K}$; using the heat flux method in their work. We have simulated the burning velocities under all experimental conditions with different models, using the Premixed code from the Chemkin Pro collection [38] with an adaptive mesh parameter GRAD $=0.05$ and a typical number of grid points 
around 400 .

Figure 16 shows that the present model yields better agreement with the experimental results than previous models, which overestimate the burning velocity over the entire range of equivalence ratios at different initial temperatures. Though slightly over-predicting the laminar burning velocities in fuel-lean and stoichiometric conditions, the present model is quite accurate in the fuel-rich regime. From the sensitivity analysis for $S_{L}$ in Fig. S10, conducted at an initial temperature of $358 \mathrm{~K}$ with $\phi=0.6,1$ and 1.4 , it is seen that reactions of small species dominate all stoichiometric ratios. This finding suggests that the Aramco Mech [52] sub-mechanism for small molecules used in the present model is somewhat more accurate than the other small molecule mechanisms tested. Only for fuel-rich conditions, the fuel-related reactions (R2) and (R7) actively participate. This could imply the viability of the DMC sub-mechanism in the present model, although more experimental and modeling efforts are needed.

\section{Summary and conclusions}

In this study, two sets of experiments were conducted to provide detailed chemical composition information for the DMC high-temperature chemical kinetics. Species mole fraction variations with temperature at 40 mbar, 200 mbar and 1040 mbar during DMC high-temperature pyrolysis were measured by combining a laminar flow tube reactor with a GC system. Furthermore, the chemical structures of low-pressure laminar premixed DMC flames with equivalence ratios of 1.0 and 1.5 were investigated with MBMS, using synchrotron VUV radiation as the ionization source. A detailed kinetic model for DMC pyrolysis and combustion was proposed based on theoretical calculation, literature review and reasonable analogies. Generally, the model performs well in reproducing the mole fraction profiles of the detected products and intermediates under our experimental conditions. The mole fraction distributions of some key species such as DME, $\mathrm{CO}_{2}$ and $\mathrm{CH}_{2} \mathrm{O}$, together with the model analysis based on sensitivity and reaction paths, indicate the major decomposition paths for fuel decomposition under different conditions. The unusual early formation of $\mathrm{CO}_{2}$ in both pyrolysis and flame conditions is of particular interest, and it is consistent with other studies of pyrolysis and oxidation of most or all alkyl ester and carbonate fuels. The production rate of $\mathrm{CO}_{2}$ was carefully analyzed, showing that this $\mathrm{CO}_{2}$ is produced directly from the carbonate and ester moieties in such fuels rather than oxidation of $\mathrm{CO}$, and that only fuel-related reactions contribute in the pyrolysis experiment, whereas small species reactions also play an essential role in premixed flames.

To better test the present model, we collected available experimental results under different conditions, including the detailed chemical structure of an opposed flow diffusion flame, and the 
global properties of ignition delay times and laminar burning velocities. All these experimental

measurements were compared to the present model, and satisfactory agreement between experiments and simulationswas reached under all tested conditions. Though low-temperature chemistry is not included, the DMC model developed in the present study appears to be broadly applicable, which could be a good starting point for model optimization and further reduction for practical applications. Further experimental studies on DMC combustion kinetics need to be conducted in the future. For example, recognizing that fuel radicals can be detected using photoelectron photoion coincidence spectroscopy (PEPICO) [62], PEPICO investigation on DMC flames can further improve the mechanism especially for the initial decomposition steps. Low-temperature oxidation studies on DMC are needed and would be extremely valuable in extending the capabilities of the present kinetic model. Studies of mixtures of DMC and hydrocarbons for the interaction chemistry are also warranted.

\section{Acknowledgement}

This research is mostly supported by the Natural Science Foundation of China (51306102, U1332208). NH is supported by the U.S. Department of Energy (USDOE), Office of Basic Energy Sciences (BES) under Grant No. DE-AC04-94-AL85000 and DE-SC0001198 (the Energy Frontier Research Center for Combustion Science). The LLNL work was performed under the auspices of the US Department of Energy by Lawrence Livermore National Laboratory under Contract DE-AC52-07NA27344 and was supported by the US Department of Energy, Office of Vehicle Technologies. The measurements were performed within the "Flame Team" collaboration at the Advanced Light Source (ALS), Lawrence Berkeley National Laboratory, Berkeley, USA, and we thank the students and postdocs for the help with the data acquisition. The experiments were profited from the expert technical assistance of Paul Fugazzi. The Advanced Light Source is supported by the Director, Office of Science, BES, USDOE under Contract No. DE-AC02-05CH11231. Sandia is a multi-program laboratory operated by Sandia Corporation, a Lockheed Martin Company, for the National Nuclear Security Administration under contract DE-AC04-94-AL85000. The authors thank Prof. Katharina Kohse-Höinghaus of Bielefeld University and Prof. Fei Qi of Shanghai Jiaotong University for their supports of this work, helpful discussions and critical review of the manuscript.

\section{References}

[1] C. K. Westbrook, W. J. Pitz, H. J. Curran, Chemical kinetic modeling study of the effects of oxygenated hydrocarbons on soot emissions from diesel engines, J. Phys. Chem. A 110 (2006) 6912-6922.

[2] N. Miyamoto, H. Ogawa, N. M. Nurun, K. Obata, T. Arima, Smokeless, low NOx, high thermal efficiency, 
and low noise diesel combustion with oxygenated agents as main fuel, SAE Technical Paper No. 980506, 1998.

[3] K. Kohse-Höinghaus, P. Oßwald, T. A. Cool, T. Kasper, N. Hansen, F. Qi, C. K. Westbrook, P. R. Westmoreland, Biofuel combustion chemistry: from ethanol to biodiesel, Angew. Chem. Int. Ed. Engl. 49 (2010) 3572-3597.

[4] L. Rubino, M. J. Thomson, The effect of oxygenated additives on soot precursor formation in a counterflow diffusion flame, SAE Technical Paper 1999-01-3589, 1999.

[5] G. Chen, W. Yu, J. Fu, J. Mo, Z. Huang, J. Yang, Z. Wang, H. Jin, F. Qi, Experimental and modeling study of the effects of adding oxygenated fuels to premixed n-heptane flames, Combust. Flame 159 (2012) 2324-2335.

[6] T. Murayama, M. Zheng, T. Chikahisa, Y.-T. Oh, Y. Fujiwara, S. Tosaka, M. Yamashita, H. Yoshitake, Simultaneous reductions of smoke and NOx from a DI diesel engine with EGR and dimethyl carbonate, SAE Technical Paper No. 952518, 1995.

[7] G. Zhang, H. Liu, X. Xia, W. Zhang, J. Fang, Effects of dimethyl carbonate fuel additive on diesel engine performances, P. I. Mech. Eng. D-J. Auto. 219 (2005) 897-903.

[8] Y. Ren, Z. Huang, H. Miao, Y. Di, D. Jiang, K. Zeng, B. Liu, X. Wang, Combustion and emissions of a DI diesel engine fuelled with diesel-oxygenate blends, Fuel 87 (2008) 2691-2697.

[9] L. B. Wen, C. Y. Xin, S. C. Yang, The effect of adding dimethyl carbonate (DMC) and ethanol to unleaded gasoline on exhaust emission, Appl. Energy 87 (2010) 115-121.

[10] A. Sinha, M. Thomson, The chemical structures of opposed flow diffusion flames of C3 oxygenated hydrocarbons (isopropanol, dimethoxy methane, and dimethyl carbonate) and their mixtures, Combust. Flame 136 (2004) 548-556.

[11] P. A. Glaude, W. J. Pitz, M. J. Thomson, Chemical kinetic modeling of dimethyl carbonate in an opposed-flow diffusion flame, Proc. Combust. Inst. 30 (2005) 1111-1118.

[12] S. Peukert, R. Sivaramakrishnan, J. Michael, High Temperature Shock Tube and Theoretical Studies on the Thermal Decomposition of Dimethyl Carbonate and Its Bimolecular Reactions with H and D-Atoms, J. Phys. Chem. A 117 (2013) 3718-3728.

[13] S. Peukert, R. Sivaramakrishnan, J. Michael, Shock tube and modeling study of the pyrolysis of dimethyl carbonate and its reaction with D-and O-atoms, 8th U. S. National Combustion Meeting (2013) Paper 070RK-0007.

[14] M. E. Bardin, E. V. Ivanov, E. J. Nilsson, V. A. Vinokurov, A. A. Konnov, Laminar burning velocities of dimethyl carbonate with air, Energy Fuels 27 (2013) 5513-5517.

[15] E. Hu, Y. Chen, Z. Zhang, L. Pan, Q. Li, Y. Cheng, Z. Huang, Experimental and kinetic study on ignition delay times of dimethyl carbonate at high temperature, Fuel 140 (2015) 626-632.

[16] Z. Wang, L. Zhao, Y. Wang, H. Bian, L. Zhang, F. Zhang, Y. Li, S. M. Sarathy, F. Qi, Kinetics of ethylcyclohexane pyrolysis and oxidation: An experimental and detailed kinetic modeling study, Combust. Flame (2015) doi:10.1016/j.combustflame.2015.03.017.

[17] Z. Wang, H. Bian, Y. Wang, L. Zhang, Y. Li, F. Zhang, F. Qi, Investigation on primary decomposition of ethylcyclohexane at atmospheric pressure, Proc. Combust. Inst. 35 (2015) 367-375.

[18] H. Pines, W. O. Haag, Alumina: Catalyst and Support. I. Alumina, its Intrinsic Acidity and Catalytic Activity1, J. Am. Chem. Soc. 82 (1960) 2471-2483. 
[19] D. Maciver, H. Tobin, R. Barth, Catalytic aluminas I. Surface chemistry of eta and gamma alumina, J. Catal. 2 (1963) 485-497.

[20] Y. Zhang, J. Cai, L. Zhao, J. Yang, H. Jin, Z. Cheng, Y. Li, L. Zhang, F. Qi, An experimental and kinetic modeling study of three butene isomers pyrolysis at low pressure, Combust. Flame 159 (2012) 905-917.

[21] T. A. Cool, K. Nakajima, T. A. Mostefaoui, F. Qi, A. McIlroy, P. R. Westmoreland, M. E. Law, L. Poisson, D. S. Peterka, M. Ahmed, Selective detection of isomers with photoionization mass spectrometry for studies of hydrocarbon flame chemistry, J. Chem. Phys. 119 (2003) 8356-8365.

[22] N. Hansen, T. A. Cool, P. R. Westmoreland, K. Kohse-Höinghaus, Recent contributions of flame-sampling molecular-beam mass spectrometry to a fundamental understanding of combustion chemistry, Prog. Energy Combust. Sci. 35 (2009) 168-191.

[23] T. A. Cool, K. Nakajima, C. A. Taatjes, A. Mcllroy, P. R. Westmoreland, M. E. Law, A. Morel, Studies of a fuel-rich propane flame with photoionization mass spectrometry, Proc. Combust. Inst. 30 (2005) 1681-1688.

[24] A. Mcilroy, T. D. Hain, H. A. Michelsen, T. A. Cool, A laser and molecular beam mass spectrometer study of low-pressure dimethyl ether flames, Proc. Combust. Inst. 28 (2000) 1647-1653.

[25] N. Hansen, M. Harper, W. Green, High-temperature oxidation chemistry of n-butanol-experiments in low-pressure premixed flames and detailed kinetic modeling, Phys. Chem. Chem. Phys. 13 (2011) 20262-20274.

[26] F. N. Egolfopoulos, N. Hansen, Y. Ju, K. Kohse-Höinghaus, C. Law, F. Qi, Advances and challenges in laminar flame experiments and implications for combustion chemistry, Prog. Energy Combust. Sci. 43 (2014) 36-67.

[27] U. Struckmeier, P. Oßwald, T. Kasper, L. Böhling, M. Heusing, M. Köhler, A. Brockhinke, K. Kohse-Höinghaus, Sampling probe influences on temperature and species concentrations in molecular beam mass spectroscopic investigations of flat premixed low-pressure flames, Z. phys. Chem 223 (2009) 503-537.

[28] P. Skovorodko, A. Tereshchenko, O. Korobeinichev, D. Knyazkov, A. Shmakov, Experimental and numerical study of probe-induced perturbations of the flame structure, Combust. Theor. Model 17 (2013) 1-24.

[29] P. Osswald, U. Struckmeier, T. Kasper, K. Kohse-Höinghaus, J. Wang, T. A. Cool, N. Hansen, P. R. Westmoreland, Isomer-specific fuel destruction pathways in rich flames of methyl acetate and ethyl formate and consequences for the combustion chemistry of esters, J. Phys. Chem. A 111 (2007) 4093-4101.

[30] J. Wang, U. Struckmeier, B. Yang, T. A. Cool, P. Osswald, K. Kohse-Höinghaus, T. Kasper, N. Hansen, P. R. Westmoreland, Isomer-Specific Influences on the Composition of Reaction Intermediates in Dimethyl Ether/Propene and Ethanol/Propene Flame, J. Phys. Chem. A 112 (2008) 9255-9265.

[31] B. Yang, C. K. Westbrook, T. A. Cool, N. Hansen, K. Kohse-Höinghaus, Photoionization mass spectrometry and modeling study of premixed flames of three unsaturated C5H8O2 esters, Proc. Combust. Inst. 34 (2013) 443-451.

[32] V. Gururajan, F. N. Egolfopoulos, K. Kohse-Höinghaus, Direct numerical simulations of probe effects in low-pressure flame sampling, Proc. Combust. Inst. 35 (2015) 821-829.

[33] B. Yang, C. K. Westbrook, T. A. Cool, N. Hansen, K. Kohse-Höinghaus, Fuel-specific influences on the composition of reaction intermediates in premixed flames of three $\mathrm{C} 5 \mathrm{H} 10 \mathrm{O} 2$ ester isomers, Phys. Chem. Chem. Phys. 13 (2011) 6901-6913.

[34] S. Dooley, F. Dryer, B. Yang, J. Wang, T. Cool, T. Kasper, N. Hansen, An experimental and kinetic modeling 
study of methyl formate low-pressure flames, Combust. Flame 158 (2011) 732-741.

[35] T. A. Cool, J. Wang, K. Nakajima, C. A. Taatjes, A. Mcllroy, Photoionization cross sections for reaction intermediates in hydrocarbon combustion, Int. J. Mass Spectrom. 247 (2005) 18-27.

[36] J. Wang, B. Yang, T. A. Cool, N. Hansen, Absolute cross-sections for dissociative photoionization of some small esters, Int. J. Mass Spectrom. 292 (2010) 14-22.

[37] B. Yang, J. Wang, T. A. Cool, N. Hansen, S. Skeen, D. L. Osborn, Absolute photoionization cross-sections of some combustion intermediates, Int. J. Mass Spectrom. 309 (2012) 118-128.

[38] R. Kee, F. Ruply, J. Miller, CHEMKIN-PRO, Reaction Design, Inc., San Diego, CA (2008).

[39] S. Dooley, M. Burke, M. Chaos, Y. Stein, F. Dryer, V. P. Zhukov, O. Finch, J. Simmie, H. Curran, Methyl formate oxidation: Speciation data, laminar burning velocities, ignition delay times, and a validated chemical kinetic model, Int. J. Chem. Kinet. 42 (2010) 527-549.

[40] L. Zhao, M. Xie, L. Ye, Z. Cheng, J. Cai, Y. Li, F. Qi, L. Zhang, Corrigendum to "An experimental and modeling study of methyl propanoate pyrolysis at low pressure"[Combust. Flame 160 (2013) 1958-1966], Combust. Flame 161 (2014) 631-632.

[41] X. Yang, D. Felsmann, N. Kurimoto, J. Krüger, T. Wada, T. Tan, E. A. Carter, K. Kohse-Höinghaus, Y. Ju, Kinetic studies of methyl acetate pyrolysis and oxidation in a flow reactor and a low-pressure flat flame using molecular-beam mass spectrometry, Proc. Combust. Inst. 35 (2015) 491-498.

[42] B. Viskolcz, G. Lendvay, L. Seres, Ab initio barrier heights and branching ratios of isomerization reactions of a branched alkyl radical, J. Phys. Chem. A 101 (1997) 7119-7127.

[43] S. Klippenstein, A. Wagner, R. Dunbar, D. Wardlaw, S. Robertson, J. Miller, Variflex 2.02m, 2010.

[44] Y. Georgievskii, J. A. Miller, M. P. Burke, S. J. Klippenstein, Reformulation and Solution of the Master Equation for Multiple-Well Chemical Reactions, J. Phys. Chem. A 117 (2013) 12146-12154.

[45] L. R. McCunn, K.-C. Lau, M. J. Krisch, L. J. Butler, J.-W. Tsung, J. J. Lin, Unimolecular dissociation of the CH3OCO radical: an intermediate in the CH3O+ CO reaction, J. Phys. Chem. A 110 (2006) 1625-1634.

[46] L. K. Huynh, K. C. Lin, A. Violi, Kinetic modeling of methyl butanoate in shock tube, J. Phys. Chem. A 112 (2008) 13470-13480.

[47] A. Farooq, D. F. Davidson, R. K. Hanson, C. K. Westbrook, A comparative study of the chemical kinetics of methyl and ethyl propanoate, Fuel 134 (2014) 26-38.

[48] N. J. Labbe, R. Sivaramakrishnan, S. J. Klippenstein, The role of radical+ fuel-radical well-skipping reactions in ethanol and methylformate low-pressure flames, Proc. Combust. Inst. 35 (2015) 447-455.

[49] W. K. Metcalfe, S. M. Burke, S. S. Ahmed, H. J. Curran, A hierarchical and comparative kinetic modeling study of C1- C2 hydrocarbon and oxygenated fuels, Int. J. Chem. Kinet. 45 (2013) 638-675.

[50] H. Wang, X. You, A. V. Joshi, S. G. Davis, A. Laskin, F. Egolfopoulos, C. K. Law USC Mech Version II. High-Temperature Combustion Reaction Model of $\mathrm{H} 2 / \mathrm{CO} / \mathrm{C} 1-\mathrm{C} 4$ Compounds. http://ignis.usc.edu/USC Mech II.htm, May 2007. .

[51] H. Wang, E. Dames, B. Sirjean, D. Sheen, R. Tangko, A. Violi, J. Lai, F. Egolfopoulos, D. Davidson, R. Hanson JetSurF version 2.0. A high-temperature chemical kinetic model of n-alkane (up to n-dodecane), cyclohexane, and methyl-, ethyl-, n-propyl and n-butyl-cyclohexane oxidation at high temperatures. http://web.stanford.edu/group/haiwanglab/JetSurF/JetSurF2.0/index.html, September 2010. . 
[52] E. R. Ritter, J. W. Bozzelli, THERM: Thermodynamic property estimation for gas phase radicals and molecules, Int. J. Chem. Kinet. 23 (1991) 767-778.

[53] J. Cai, W. Yuan, L. Ye, Z. Cheng, Y. Wang, L. Zhang, F. Zhang, Y. Li, F. Qi, Experimental and kinetic modeling study of 2-butanol pyrolysis and combustion, Combust. Flame 160 (2013) 1939-1957.

[54] L. Zhao, M. Xie, L. Ye, Z. Cheng, J. Cai, Y. Li, F. Qi, L. Zhang, An experimental and modeling study of methyl propanoate pyrolysis at low pressure, Combust. Flame 160 (2013) 1958-1966.

[55] Z. Zhao, M. Chaos, A. Kazakov, F. L. Dryer, Thermal decomposition reaction and a comprehensive kinetic model of dimethyl ether, Int. J. Chem. Kinet. 40 (2008) 1-18.

[56] J. Cai, L. Zhang, F. Zhang, Z. Wang, Z. Cheng, W. Yuan, F. Qi, Experimental and kinetic modeling study of n-butanol pyrolysis and combustion, Energy Fuels 26 (2012) 5550-5568.

[57] K. C. Lin, J. Y. Lai, A. Violi, The role of the methyl ester moiety in biodiesel combustion: A kinetic modeling comparison of methyl butanoate and n-butane, Fuel 92 (2012) 16-26.

[58] C. K. Westbrook, W. J. Pitz, P. R. Westmoreland, F. L. Dryer, M. Chaos, P. Oßwald, K. Kohse-Höinghaus, T. A. Cool, J. Wang, B. Yang, A detailed chemical kinetic reaction mechanism for oxidation of four small alkyl esters in laminar premixed flames, Proc. Combust. Inst. 32 (2009) 221-228.

[59] C. J. Pope, J. A. Miller, Exploring old and new benzene formation pathways in low-pressure premixed flames of aliphatic fuels, Proc. Combust. Inst. 28 (2000) 1519-1527.

[60] J. A. Miller, S. J. Klippenstein, The recombination of propargyl radicals and other reactions on a C6H6 potential, J. Phys. Chem. A 107 (2003) 7783-7799.

[61] Y. L. Wang, D. J. Lee, C. K. Westbrook, F. N. Egolfopoulos, T. T. Tsotsis, Oxidation of small alkyl esters in flames, Combust. Flame 161 (2014) 810-817.

[62] D. Felsmann, K. Moshammer, J. Krüger, A. Lackner, A. Brockhinke, T. Kasper, T. Bierkandt, E. Akyildiz, N. Hansen, A. Lucassen, Electron ionization, photoionization and photoelectron/photoion coincidence spectroscopy in mass-spectrometric investigations of a low-pressure ethylene/oxygen flame, Proc. Combust. Inst. 35 (2015) 779-786. 
Figure captions:

Fig. 1. (a) The schematic diagram of pyrolysis apparatus with a GC. (b) The temperature profiles along the centerline of the flow tube are measured by moving an S-type thermocouple from the tube inlet to the sampling point of the quartz tube. Three temperature profiles are shown to illustrate the variation along the tube.

Fig. 2. Schematic structures of dimethyl carbonate (DMC) and methyl formate $\left(\mathrm{CH}_{3} \mathrm{OCHO}\right)$. The numbers refer to bond dissociation energies (BDEs) [11,39] in the unit of $\mathrm{kcal} / \mathrm{mol}$.

Fig. 3. Experimental mole fraction profiles (symbols) and modeling results (lines) of DMC, $\mathrm{CO}, \mathrm{DME}$ and $\mathrm{CO}_{2}$ from DMC pyrolysis in a laminar flow reactor at various pressures. Solid lines: present model; dashed lines: Glaude model [11]; dotted lines: Hu model [15].

Fig. 4. Experimental mole fraction profiles (symbols) and modeling results (lines) of minor species $\left(\mathrm{CH}_{4}, \mathrm{C}_{2} \mathrm{H}_{2}\right.$, $\mathrm{C}_{2} \mathrm{H}_{4}, \mathrm{C}_{2} \mathrm{H}_{2}$ ) from DMC pyrolysis in a laminar flow reactor at various pressures. Solid lines: present model; dashed lines: Glaude model [11]; dotted lines: Hu model [15].

Fig. 5. Reaction pathways for DMC pyrolysis at approximately $50 \%$ fuel consumed in a laminar flow reactor. The thickness of each arrow represents the reaction flux of the corresponding reaction, and the numbers are percent contribution to the consumption of the species on the source side of the arrow at 1040 mbar, 200 mbar (in parentheses) and 40 mbar [in square brackets].

Fig.6. Sensitivity of DMC fraction to reaction rate A-factors in a flow reactor at approximately $50 \%$ fuel consumed under various pressures. Only the eight most important reactions are listed.

Fig. 7. Experimental (symbol) and simulated (lines) DMC mole fraction profiles (Left axis), using different values of $k_{1}$ and $k_{2}$ at different pressures and the $k_{1} / k_{2}$ ratios from the present work and Peukert et al.[12] (Right axis). Solid lines: $k_{1}$ and $k_{2}$ from present work; shadowed areas: variation range of DMC mole profiles within the uncertainty of calculated $k_{1}$ and $k_{2}$ in the present work; dashed lines: $k_{1}$ and $k_{2}$ from Peukert et al. [12]; dashed dot lines: $k_{1} / k_{2}$ ratios from different works.

Fig. 8. Normalized ROP coefficients for $\mathrm{CO}_{2}$ (left axis) and simulated $\mathrm{CO}_{2}$ mole fraction profile (right axis) as a function of temperature at 40 mbar. Lines with symbols: percentages of $\mathrm{CO}_{2}$ formation contributed from R1, R20 and R21; dashed lines: simulated $\mathrm{CO}_{2}$ mole fraction at 40 mbar.

Fig. 9. Experimental mole fraction profiles (symbols) and modeling results (solid lines) of major species in laminar premixed DMC flames. Dashed lines: measured temperature profiles.

Fig. 10. Experimental mole fraction profiles (symbols) and modeling results (solid lines) of hydrocarbon intermediates in laminar premixed DMC flames. Black: $\phi=1.0$ DMC flame; Red: $\phi=1.5$ DMC flame. Solid lines: present model; dashed lines: Glaude model [11]; dotted lines: Hu model [15].

Fig. 11. Experimental mole fraction profiles (symbols) and modeling results (solid lines) of oxygenated intermediates in laminar premixed DMC flames. Black: $\phi=1.0$ DMC flame; Red: $\phi=1.5$ DMC flame. Solid lines: present model; dashed lines: Glaude model [11]; dotted lines: Hu model [15].

Fig. 12. Reaction pathways for DMC in low-pressure laminar premixed flames based on the integrated ROP analysis along the entire flame. The thickness of each arrow represents the reaction flux of the corresponding reaction, and the numbers are percent contribution to the consumption of the species on the source side of the arrow in the $\phi=1.0$ flame and $\phi=1.5$ flame (in parenthesis).

Fig. 13. ROP analysis for $\mathrm{CO}_{2}$ (left axis) and simulated $\mathrm{CO}_{2}$ mole fractions (right axis) along the distance from burner in the two DMC flames. Solid lines: contribution to $\mathrm{CO}_{2}$ formation from each reaction; dashed lines: simulated mole fraction profiles of $\mathrm{CO}_{2}$.

Fig.14. Experimental [10] and modeling results of the chemical structure of an opposed flow flame. (Symbol: 
measured profiles; lines: simulated values with present model)

Fig. 15. Experimental [15] and modeling results of ignition delay times for $\mathrm{DMC} / \mathrm{O}_{2} / \mathrm{Ar}$ mixtures in a shock tube under various conditions. (Symbols: measured profiles; lines: simulated values with the present model) Solid lines: present model; dashed lines: Glaude model [11].

Fig. 16. Experimental [14] and modeling results of burning velocities for DMC/air flames. (Symbols: measured profiles; lines: simulated values) Solid lines: present model; dashed lines: Glaude model [11]; dotted lines: Hu model [15]. 
Table 1

Experimental conditions for DMC studies in the present work and the literature.

\begin{tabular}{|c|c|c|c|c|c|c|c|c|}
\hline \multirow{2}{*}{ Experiments } & \multirow{2}{*}{ Temperature } & \multirow{2}{*}{ Pressure } & \multirow{2}{*}{ Equivalence ratio } & \multirow{2}{*}{$\begin{array}{l}\mathrm{D}_{\mathrm{M}}^{\mathrm{a}} \\
\left(\mathrm{g} / \mathrm{s} / \mathrm{cm}^{2}\right)\end{array}$} & \multicolumn{3}{|c|}{ Flow rate $\left(\operatorname{slm}^{\mathrm{b}}\right)$} & \multirow{2}{*}{ Ref. } \\
\hline & & & & & DMC & $\mathrm{O}_{2}$ & $\mathrm{Ar}$ & \\
\hline \multirow[t]{2}{*}{ Laminar premixed flame } & $500 \sim 2242 \mathrm{~K}$ & 26.66 mbar (20.00 Torr) & 1.0 & 0.00472 & 0.75 & 2.25 & 1.00 & present work \\
\hline & $500 \sim 2319 \mathrm{~K}$ & 33.33 mbar (25.00 Torr) & 1.5 & 0.00511 & 1.00 & 2.00 & 1.00 & \\
\hline \multirow[t]{3}{*}{ Laminar flow reactor } & 939 1490 K & 40 mbar (30.00 Torr) & $\infty$ & & 0.02 & 0.00 & 0.98 & present work \\
\hline & $842 \sim 1337 \mathrm{~K}$ & 200 mbar (150.00 Torr) & & & & & & \\
\hline & $903 \sim 1221 \mathrm{~K}$ & 1040 mbar (780.00 Torr) & & & & & & \\
\hline Opposed flow diffusion flame & $300 \sim 1624 \mathrm{~K}$ & $1 \mathrm{~atm}$ & --- & & & & & {$[10]$} \\
\hline Laminar flame speed & $\mathrm{T}_{0}=298,318,338,358 \mathrm{~K}$ & $1 \mathrm{~atm}$ & $0.6 \sim 1.6$ & & & & & {$[14]$} \\
\hline Ignition delay time (Shock tube) & $1100 \sim 1600 \mathrm{~K}$ & $0.12,0.5,1.0 \mathrm{MPa}$ & $0.5,1.0,2.0$ & & & & & {$[15]$} \\
\hline
\end{tabular}

\footnotetext{
${ }^{\mathrm{a}}$ inlet mass flow rate

${ }^{\mathrm{b}}$ standard liter per minute
} 
Table2

DMC sub-mechanism. Rate coefficients are given as $\mathrm{k}=\mathrm{A} \mathrm{T}^{\mathrm{n}} \exp \left(-\mathrm{E}_{\mathrm{a}} / \mathrm{kT}\right)$. Units are $\mathrm{s}^{-1}, \mathrm{~cm}^{3}$ and cal $/ \mathrm{mol}$.

\begin{tabular}{|c|c|c|c|c|c|}
\hline No. & Reactions & $\bar{A}$ & $n$ & $E_{a}$ & Ref. \\
\hline$\overline{\mathrm{R} 1}$ & $\mathrm{COC}^{*} \mathrm{OOC}=\mathrm{CH}_{3} \mathrm{OCH}_{3}+\mathrm{CO}_{2}$ & $1.49 \times 10^{43}$ & -8.53 & $8.47 \times 10^{4}$ & present work \\
\hline R2 & $\mathrm{COC} * \mathrm{OOC}=\mathrm{COC} * \mathrm{OOj}+\mathrm{CH}_{3}$ & $1.29 \times 10^{64}$ & -13.89 & $1.09 \times 10^{5}$ & present work \\
\hline R3 & $\mathrm{COC} * \mathrm{OOC}=\mathrm{CH}_{3} \mathrm{OCHO}+\mathrm{CH}_{2} \mathrm{O}$ & $2.82 \times 10^{59}$ & -13.83 & $1.11 \times 10^{5}$ & present work \\
\hline R4 & $\mathrm{COC} * \mathrm{OOC}=\mathrm{COC} * \mathrm{OOCH}+\mathrm{H}_{2}$ & $8.87 \times 10^{63}$ & -15.00 & $1.17 \times 10^{5}$ & present work \\
\hline R5 & $\mathrm{COC}^{*} \mathrm{OOC}=\mathrm{COC} * \mathrm{OOC} \mathrm{j}+\mathrm{H}$ & $8.87 \times 10^{63}$ & -15.00 & $1.17 \times 10^{5}$ & present work \\
\hline R6 & $\mathrm{COC} * \mathrm{OOC}=\mathrm{CH}_{3} \mathrm{OCO}+\mathrm{CH}_{3} \mathrm{O}$ & $1.99 \times 10^{73}$ & -16.91 & $1.24 \times 10^{5}$ & present work \\
\hline R7 & $\mathrm{COC} * \mathrm{OOC}+\mathrm{H}=\mathrm{COC} * \mathrm{OOC} \mathrm{j}+\mathrm{H}_{2}$ & $8.73 \times 10^{4}$ & 2.83 & $6.75 \times 10^{3}$ & {$[12,13]$} \\
\hline R8 & $\mathrm{COC}^{*} \mathrm{OOC}+\mathrm{O}=\mathrm{COC} * \mathrm{OOC} \mathrm{j}+\mathrm{OH}$ & $1.13 \times 10^{4}$ & 2.92 & $4.65 \times 10^{3}$ & {$[12,13]$} \\
\hline R9 & $\mathrm{COC} * \mathrm{OOC}+\mathrm{O}_{2}=\mathrm{COC} * \mathrm{OOC} \mathrm{j}+\mathrm{HO}_{2}$ & $3.07 \times 10^{13}$ & 0.08 & $5.17 \times 10^{4}$ & adapted from [39] \\
\hline $\mathrm{R} 10$ & $\mathrm{COC} * \mathrm{OOC}+\mathrm{OH}=\mathrm{COC} * \mathrm{OOCj}+\mathrm{H}_{2} \mathrm{O}$ & $1.77 \times 10^{13}$ & 0.05 & $3.34 \times 10^{3}$ & adapted from [39] \\
\hline R11 & $\mathrm{COC} * \mathrm{OOC}+\mathrm{CH}_{3}=\mathrm{COC} * \mathrm{OOCj}+\mathrm{CH}_{4}$ & $5.82 \times 10^{-1}$ & 3.70 & $6.82 \times 10^{3}$ & adapted from [39] \\
\hline $\mathrm{R} 12$ & $\mathrm{COC} * \mathrm{OOC}+\mathrm{HO}_{2}=\mathrm{COC} * \mathrm{OOCj}+\mathrm{H}_{2} \mathrm{O}_{2}$ & $1.13 \times 10^{5}$ & 2.44 & $1.66 \times 10^{4}$ & adapted from [39] \\
\hline $\mathrm{R} 13$ & $\mathrm{COC} * \mathrm{OOC}+\mathrm{CH}_{3} \mathrm{O}_{2}=\mathrm{COC} * \mathrm{OOCj}+\mathrm{CH}_{3} \mathrm{O}_{2} \mathrm{H}$ & $1.13 \times 10^{5}$ & 2.44 & $1.66 \times 10^{4}$ & adapted from [39] \\
\hline $\mathrm{R} 14$ & $\mathrm{COC} * \mathrm{OOC}+\mathrm{CH}_{3} \mathrm{O}=\mathrm{COC} * \mathrm{OOCj}+\mathrm{CH}_{3} \mathrm{OH}$ & $9.18 \times 10^{9}$ & 0.45 & $4.82 \times 10^{3}$ & adapted from [39] \\
\hline $\mathrm{R} 15$ & $\mathrm{COC} * \mathrm{OOC}+\mathrm{C}_{2} \mathrm{H}_{3}=\mathrm{COC} * \mathrm{OOCj}+\mathrm{C}_{2} \mathrm{H}_{4}$ & $2.00 \times 10^{11}$ & 0.00 & $1.04 \times 10^{4}$ & adapted from [39] \\
\hline $\mathrm{R} 16$ & $\mathrm{COC} * \mathrm{OOC}+\mathrm{C}_{2} \mathrm{H}_{5}=\mathrm{COC} * \mathrm{OOCj}+\mathrm{C}_{2} \mathrm{H}_{6}$ & $2.00 \times 10^{11}$ & 0.00 & $1.04 \times 10^{4}$ & adapted from [39] \\
\hline R17 & $\mathrm{COC}^{*} \mathrm{OOC}+\mathrm{HCO}=\mathrm{COC}^{*} \mathrm{OOCj}+\mathrm{CH}_{2} \mathrm{O}$ & $2.05 \times 10^{5}$ & 2.50 & $1.84 \times 10^{4}$ & adapted from [39] \\
\hline $\mathrm{R} 18$ & $\mathrm{COC}^{*} \mathrm{OOC}+\mathrm{CH}_{3} \mathrm{OCO}=\mathrm{COC} * \mathrm{OOCj}+\mathrm{CH}_{3} \mathrm{OCHO}$ & $2.00 \times 10^{11}$ & 0.00 & $1.04 \times 10^{4}$ & adapted from [39] \\
\hline $\mathrm{R} 19$ & $\mathrm{COC} * \mathrm{OOCj}=\mathrm{CH}_{3} \mathrm{OCO}+\mathrm{CH}_{2} \mathrm{O}$ & $5.60 \times 10^{12}$ & 0.63 & $1.51 \times 10^{4}$ & present work \\
\hline R20 & $\mathrm{COC}^{*} \mathrm{OOj}=\mathrm{CH}_{3} \mathrm{O}+\mathrm{CO}_{2}$ & $1.61 \times 10^{14}$ & 0.09 & $1.64 \times 10^{4}$ & present work \\
\hline
\end{tabular}




$\begin{array}{llllll}\mathrm{R} 21 & \mathrm{CH}_{3} \mathrm{OCO}=\mathrm{CH}_{3}+\mathrm{CO}_{2} & 1.89 \times 10^{9} & 0.13 & 7.97 \times 10^{3} & {[40]} \\ \mathrm{R} 22 & \mathrm{CH}_{3} \mathrm{OCO}=\mathrm{CH}_{3} \mathrm{O}+\mathrm{CO} & 6.11 \times 10^{-2} & 2.95 & 1.78 \times 10^{4} & {[40]} \\ \mathrm{R} 23 & \mathrm{COC} * \mathrm{OOCj}+\mathrm{CH}_{3}=>\mathrm{COC} * \mathrm{OOj}+\mathrm{C}_{2} \mathrm{H}_{5} & 1.00 \times 10^{13} & 0.00 & 0.00 & {[41]}\end{array}$

COC*OOC: $\mathrm{CH}_{3} \mathrm{OC}(=\mathrm{O}) \mathrm{OCH}_{3}$;

COC*OOj: $\mathrm{CH}_{3} \mathrm{OC}(=\mathrm{O}) \mathrm{O}$;

$\mathrm{COC} * \mathrm{OOCj}: \mathrm{CH}_{3} \mathrm{OC}(=\mathrm{O}) \mathrm{OCH}_{2}$;

COC $* \mathrm{OOCH}: \mathrm{CH}_{3} \mathrm{OC}(=\mathrm{O}) \mathrm{OCH}$;

$\mathrm{COC} * \mathrm{OOCj}: \mathrm{CH}_{3} \mathrm{OC}(=\mathrm{O})$. 
(a)

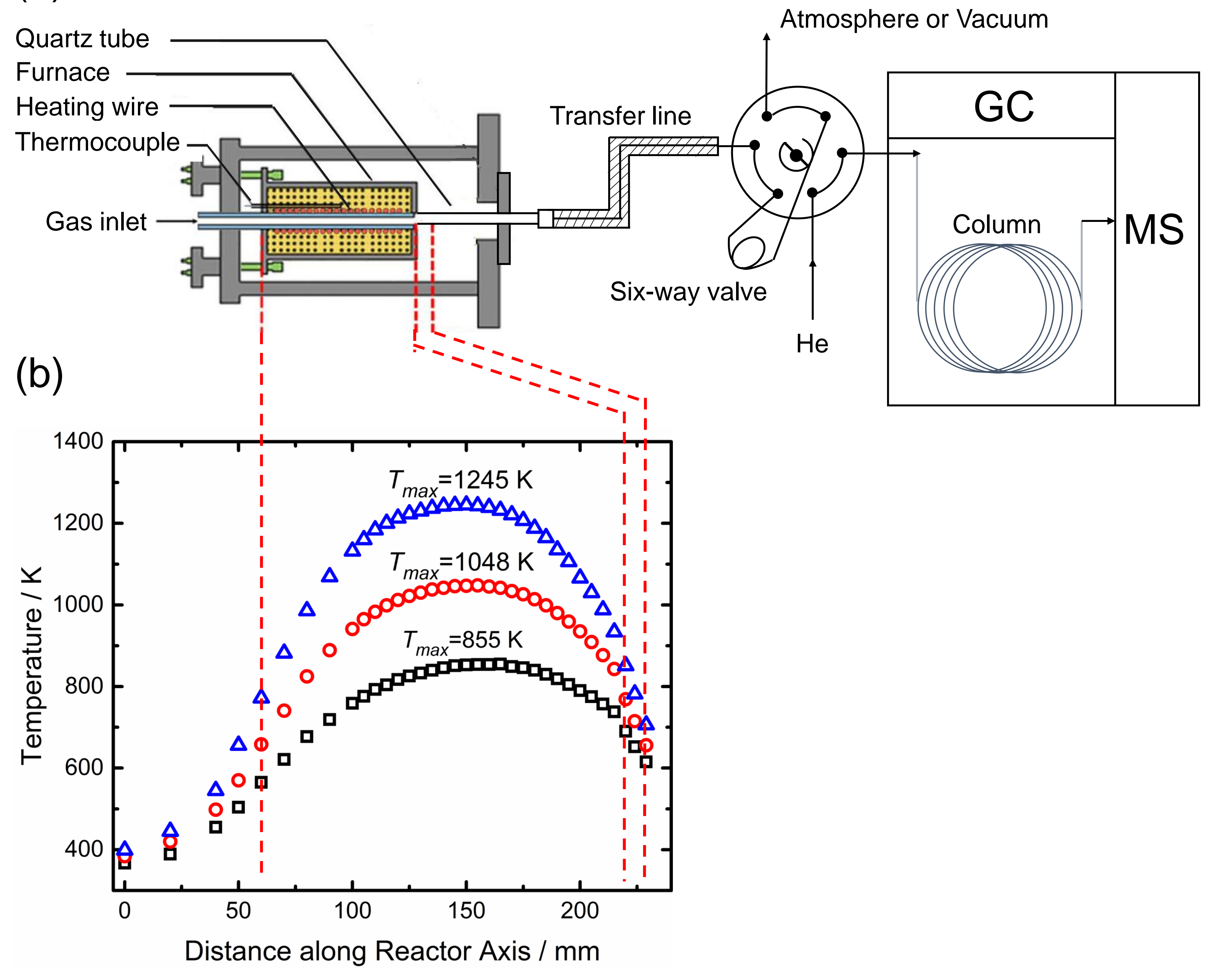




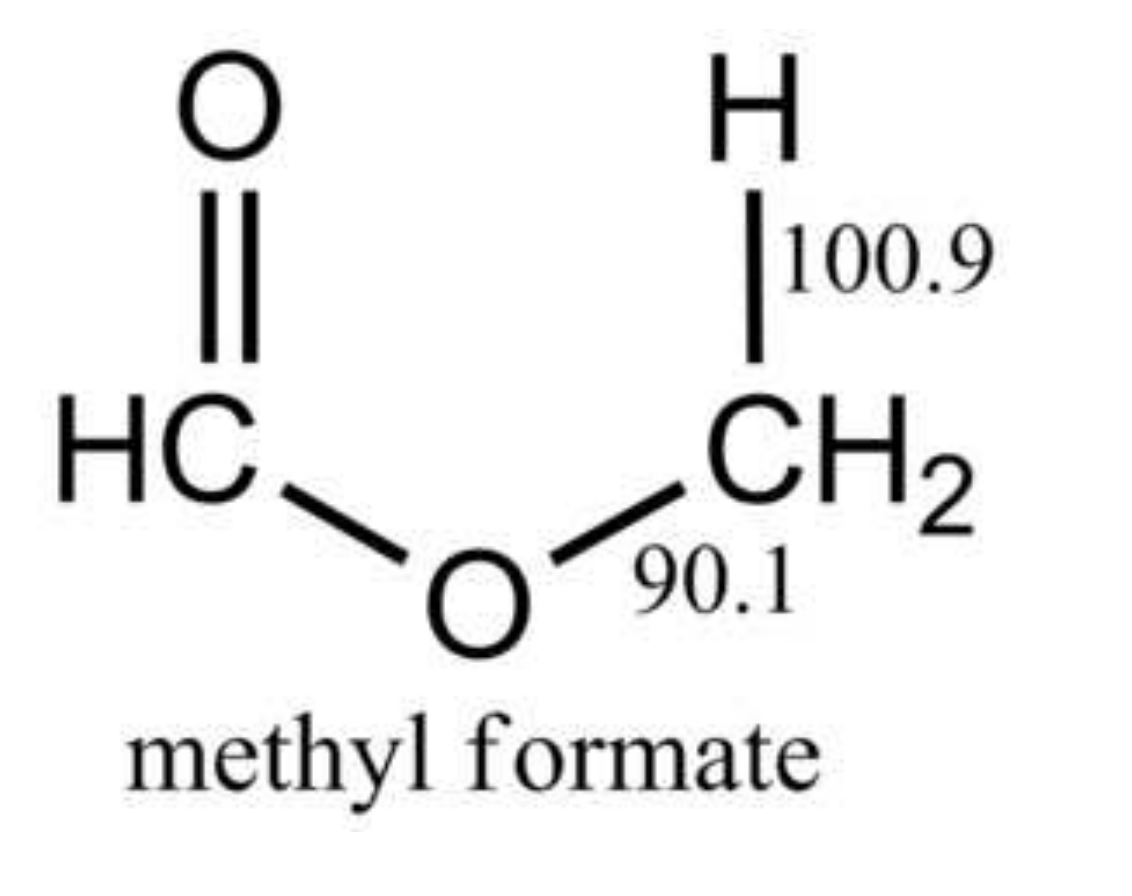
101.1
$\mathrm{H}$ $102.2 \mathrm{O} 89.6$ $x^{2}$ methyl formate

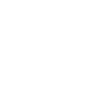

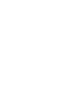

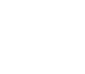

\section{dimethyl carbonate}

2

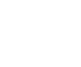

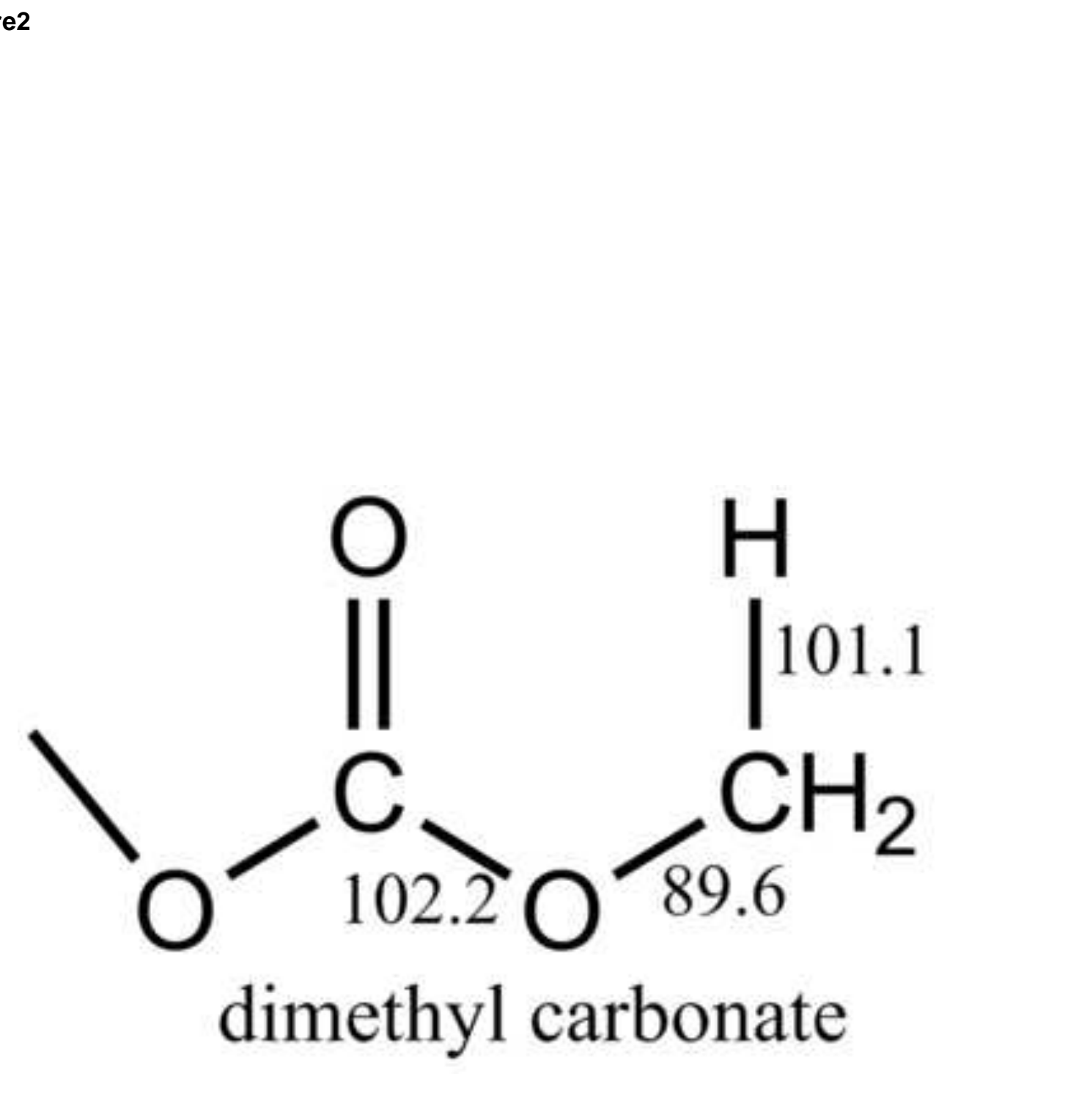

Hof




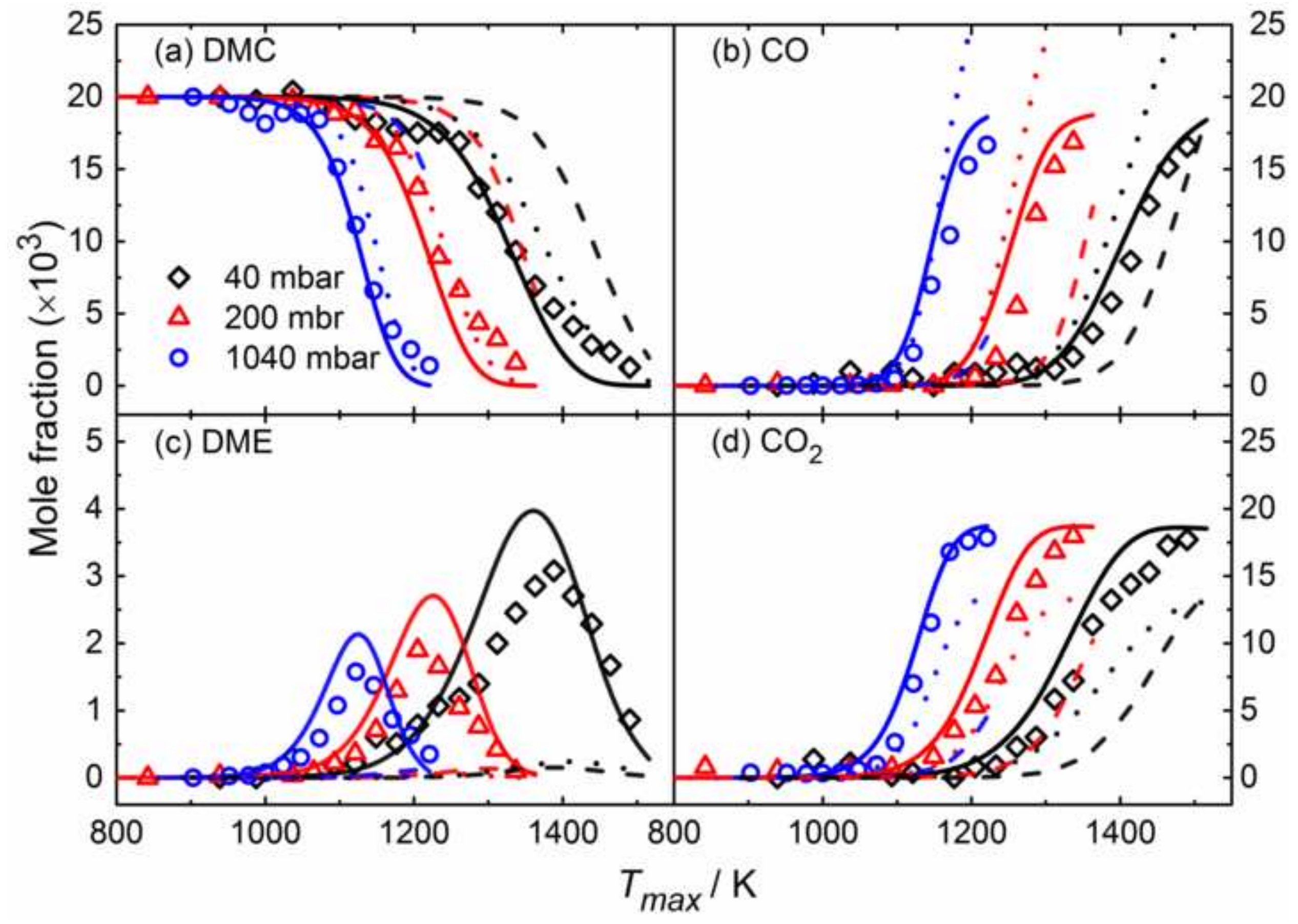




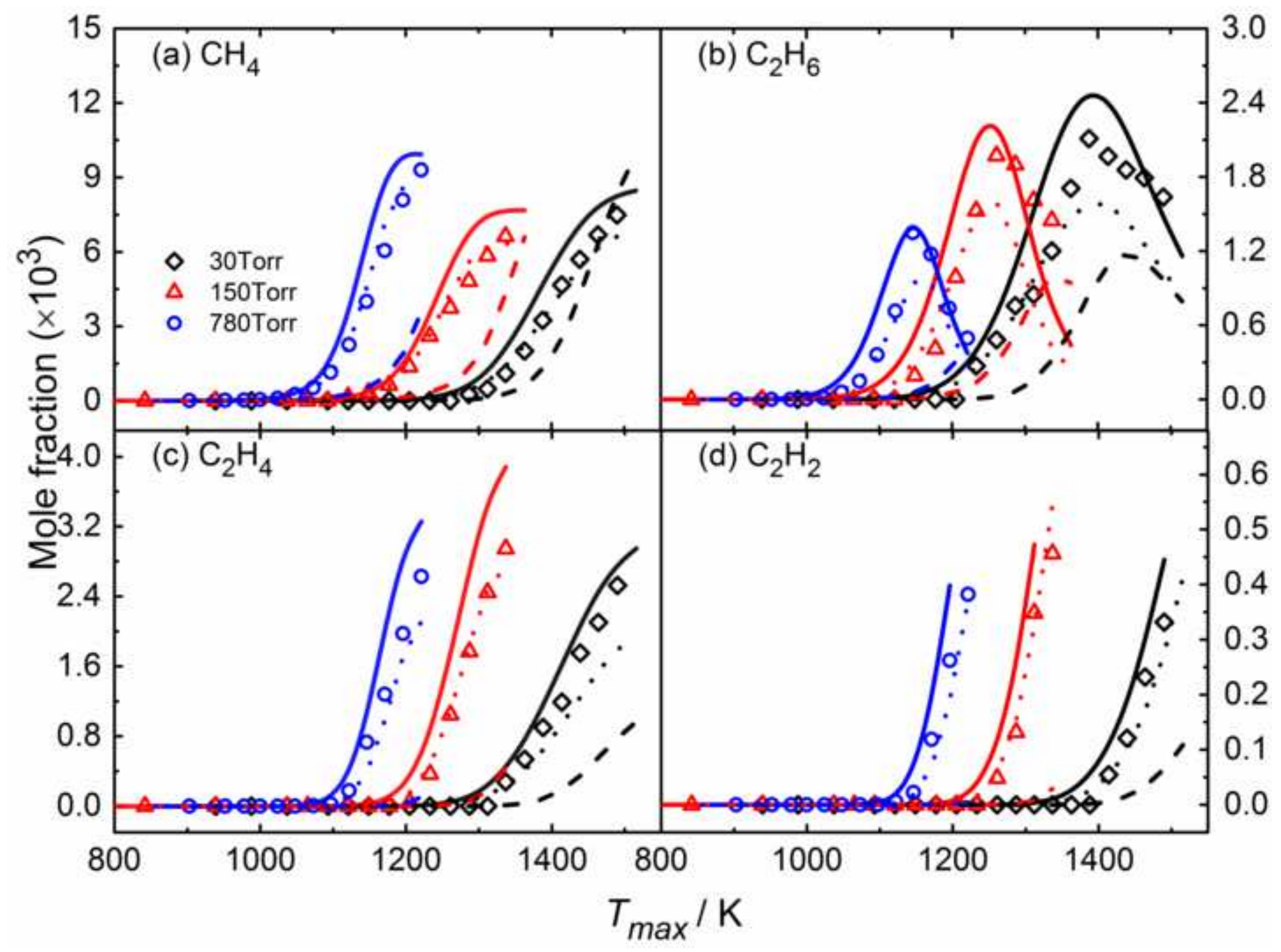




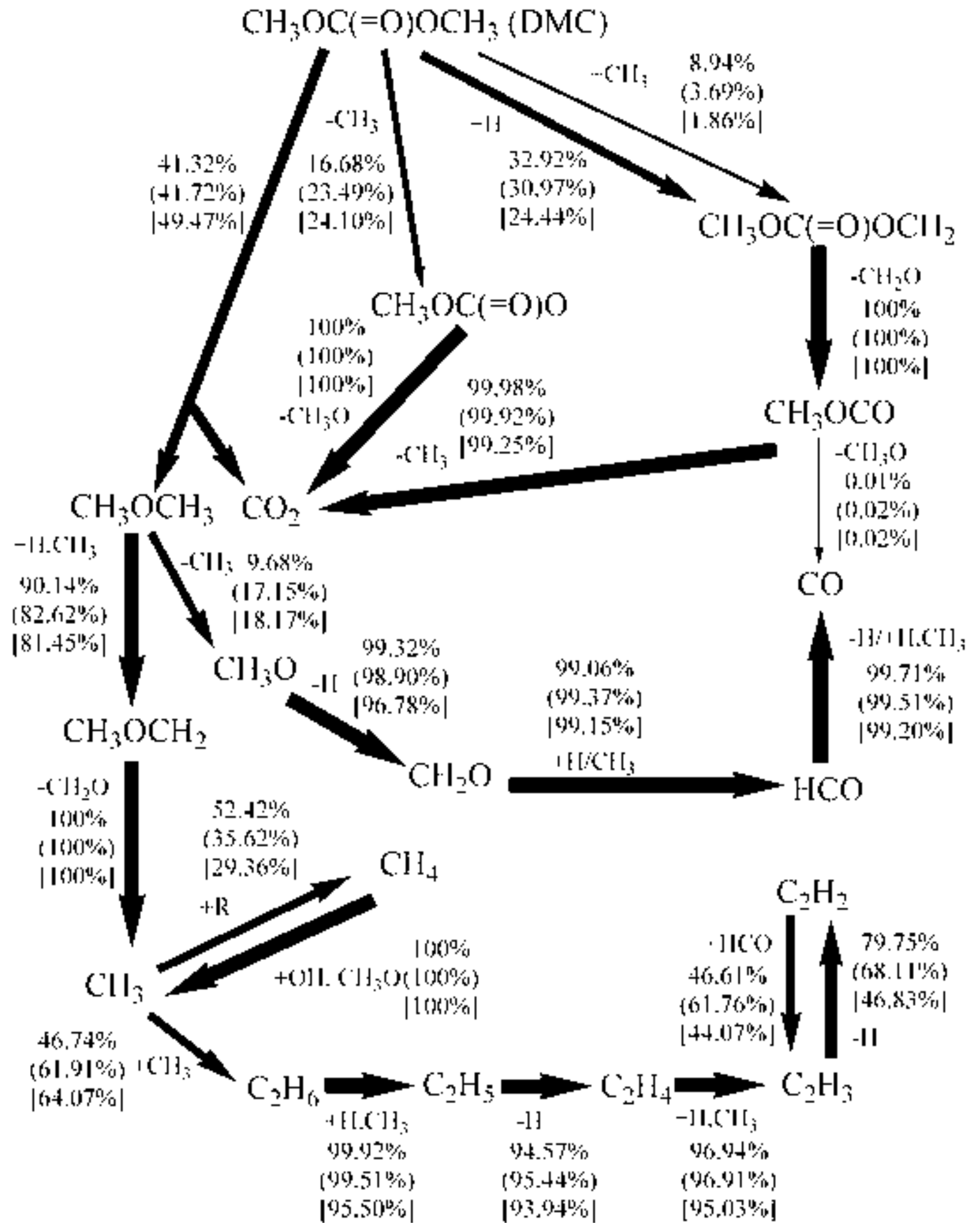




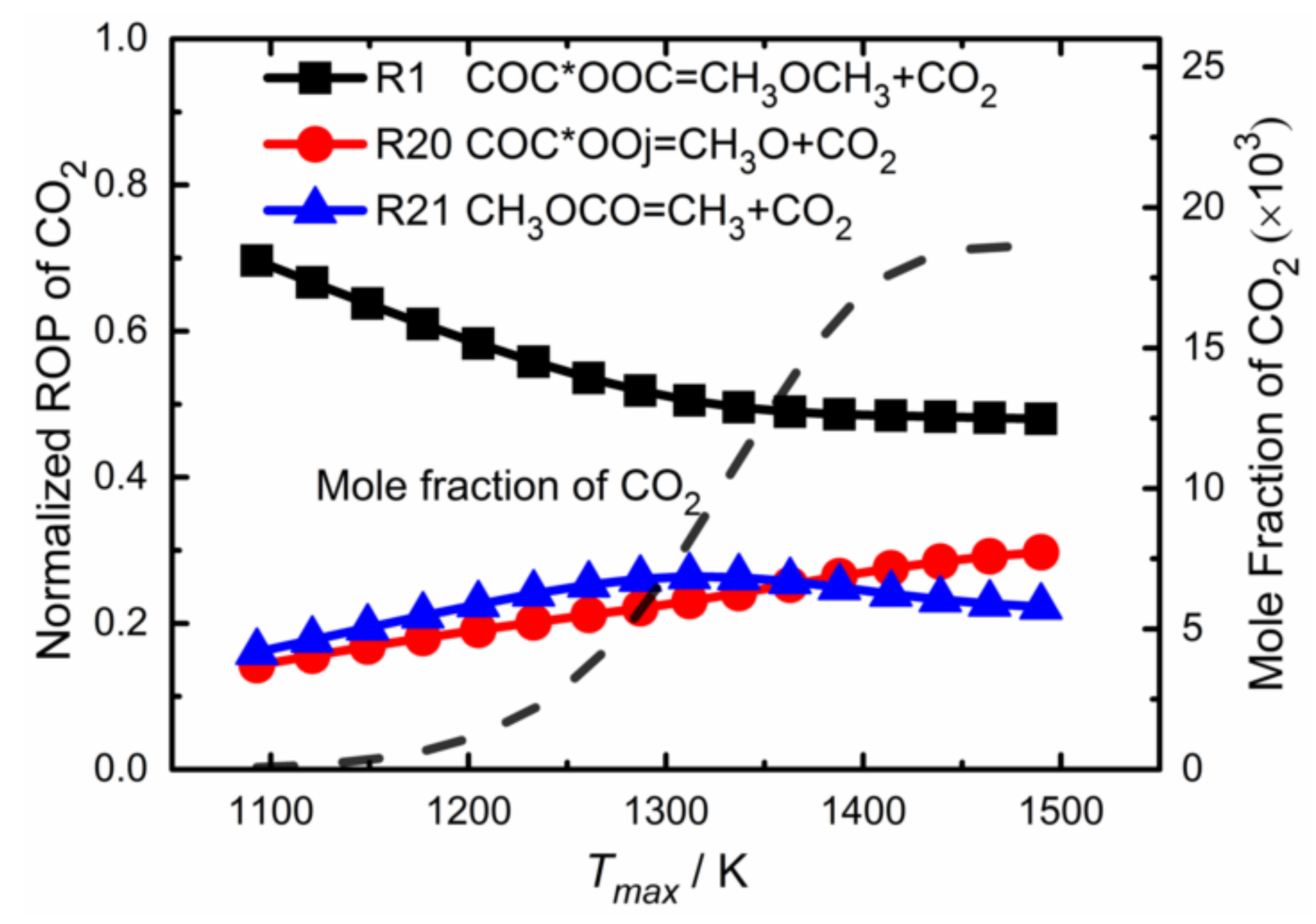




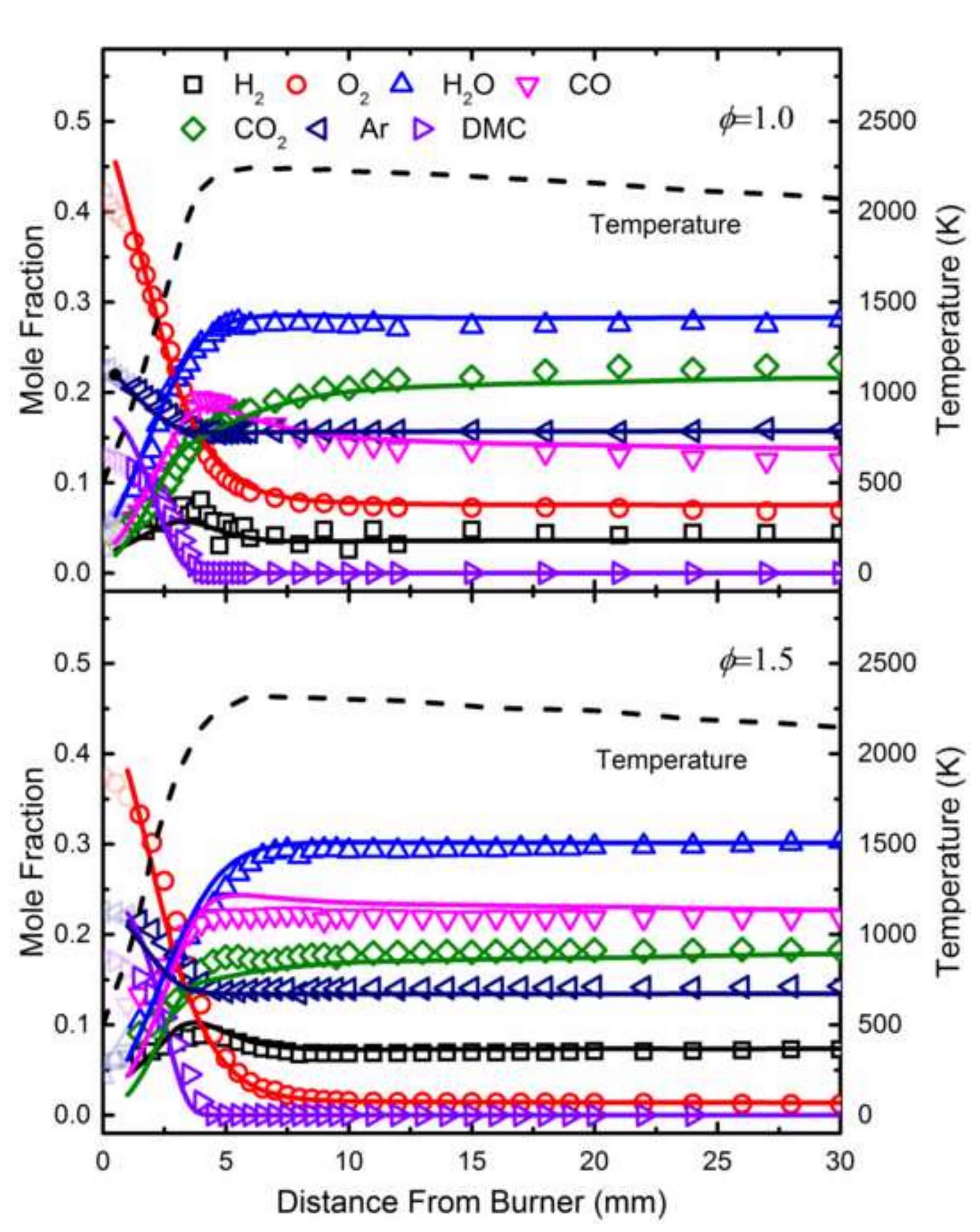

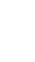



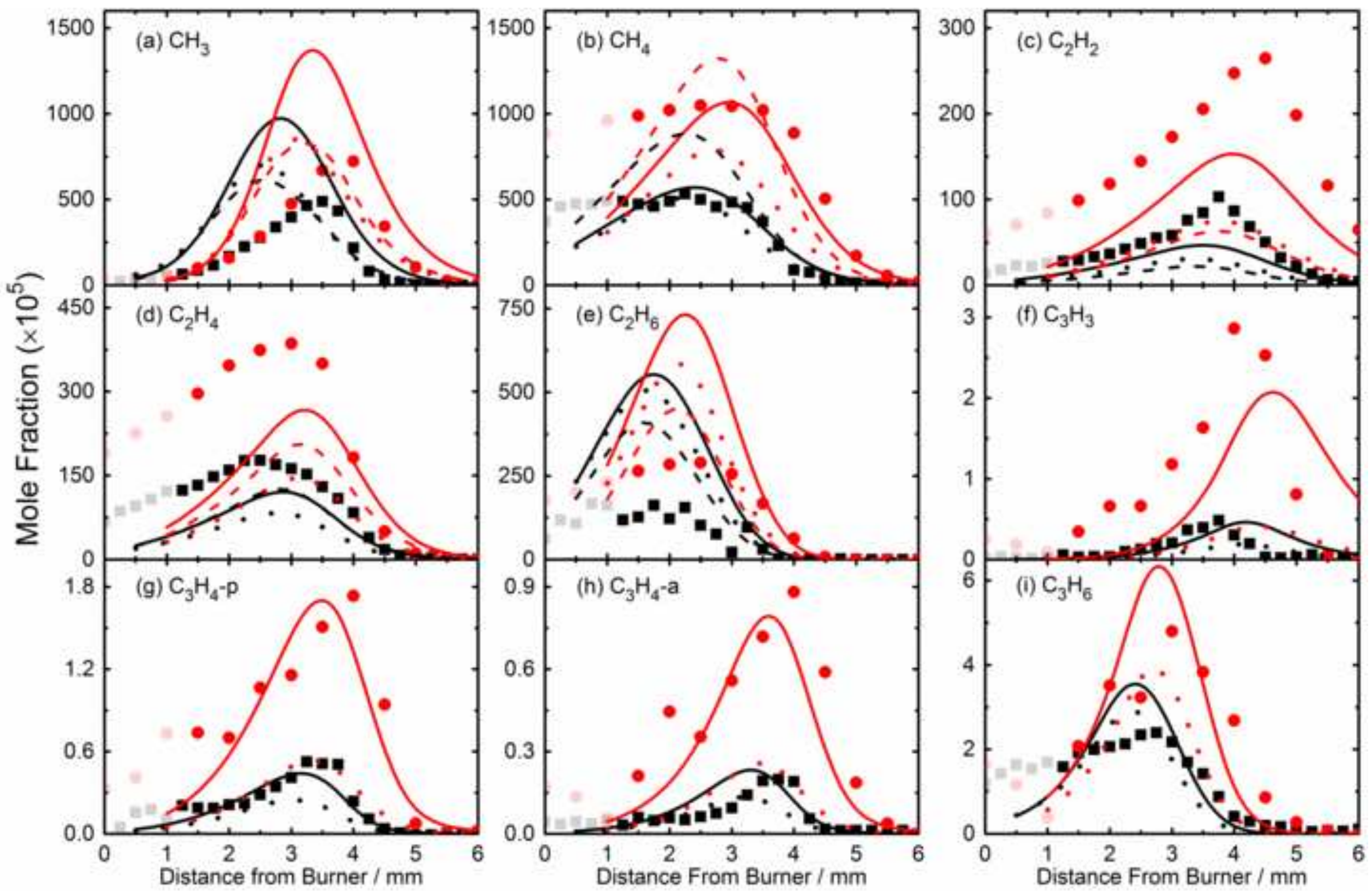

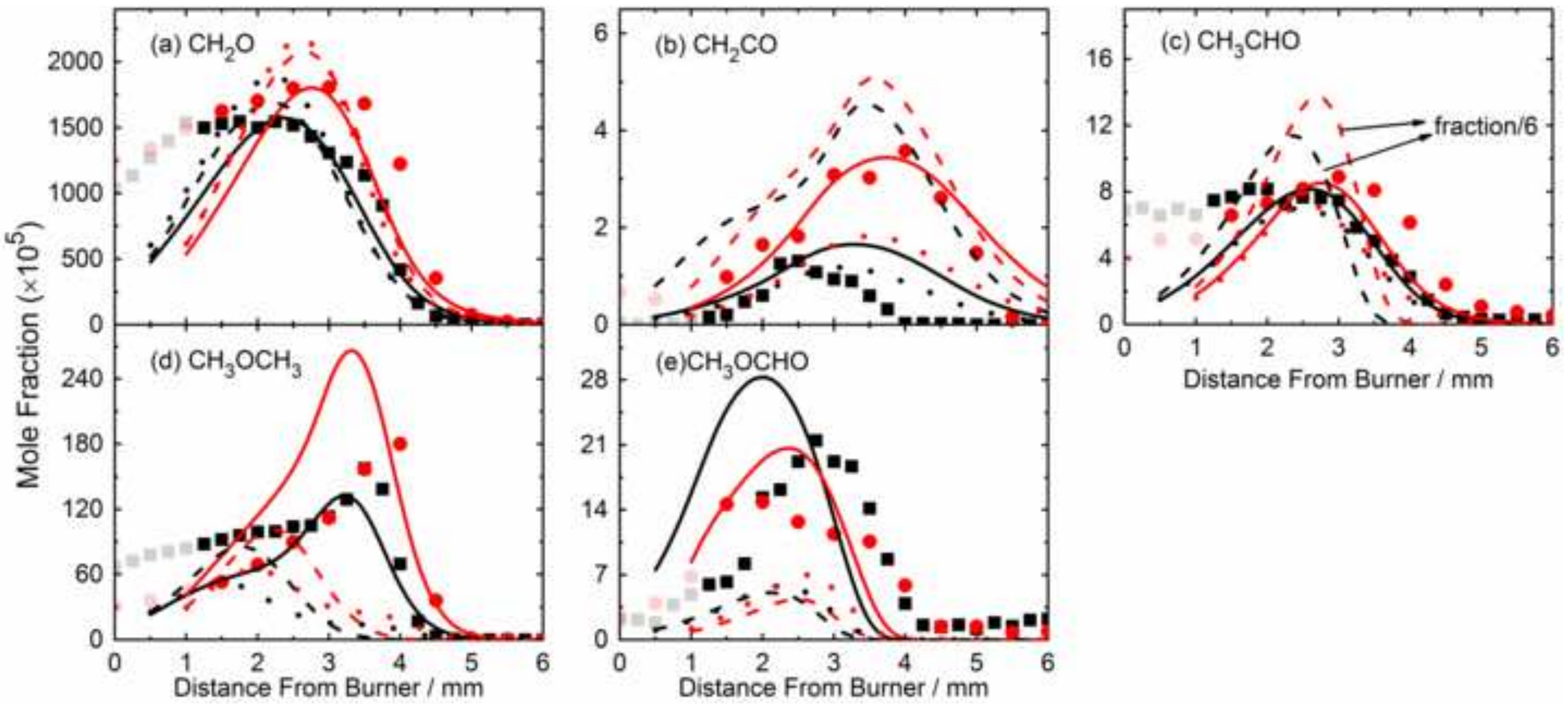


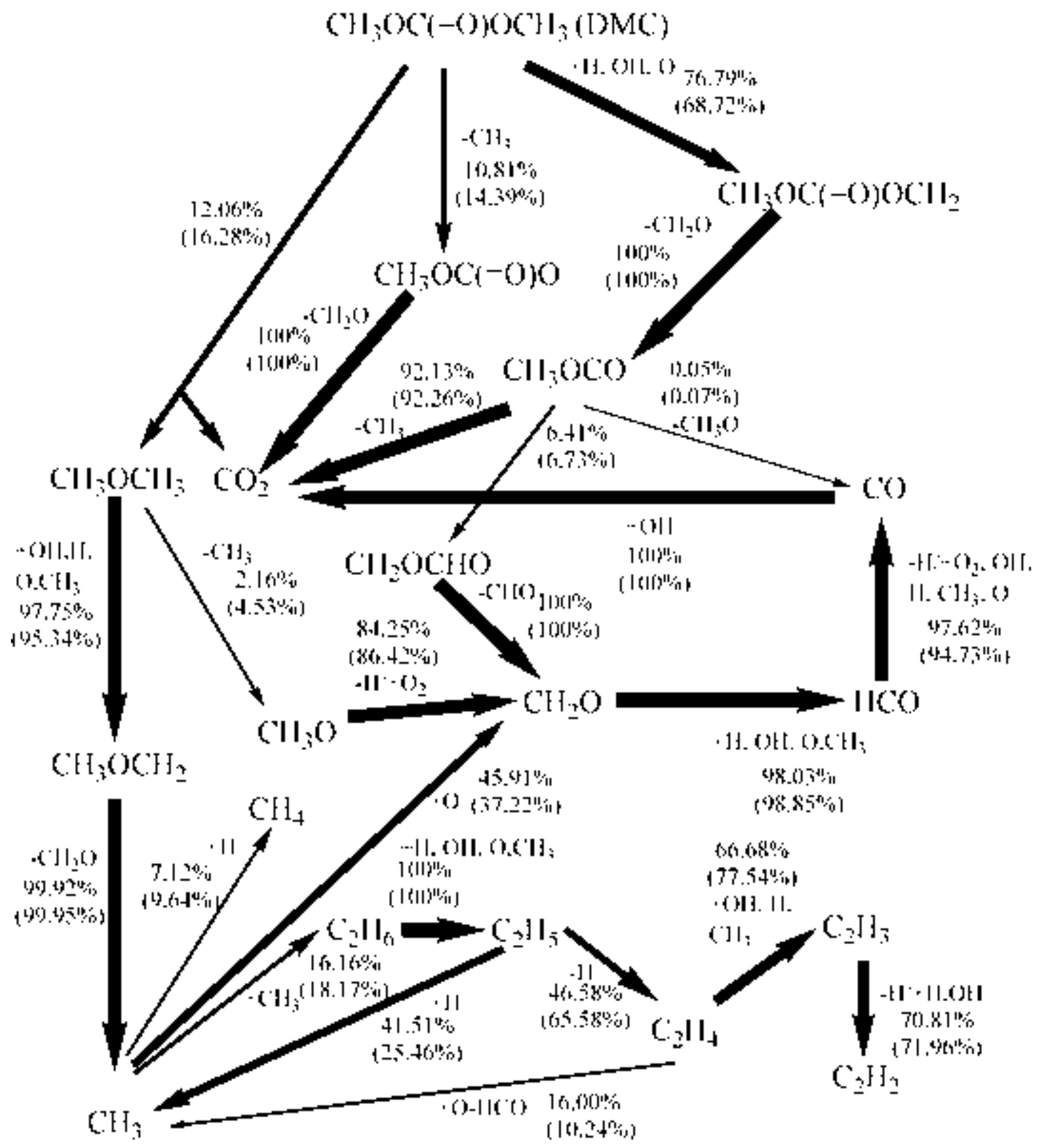




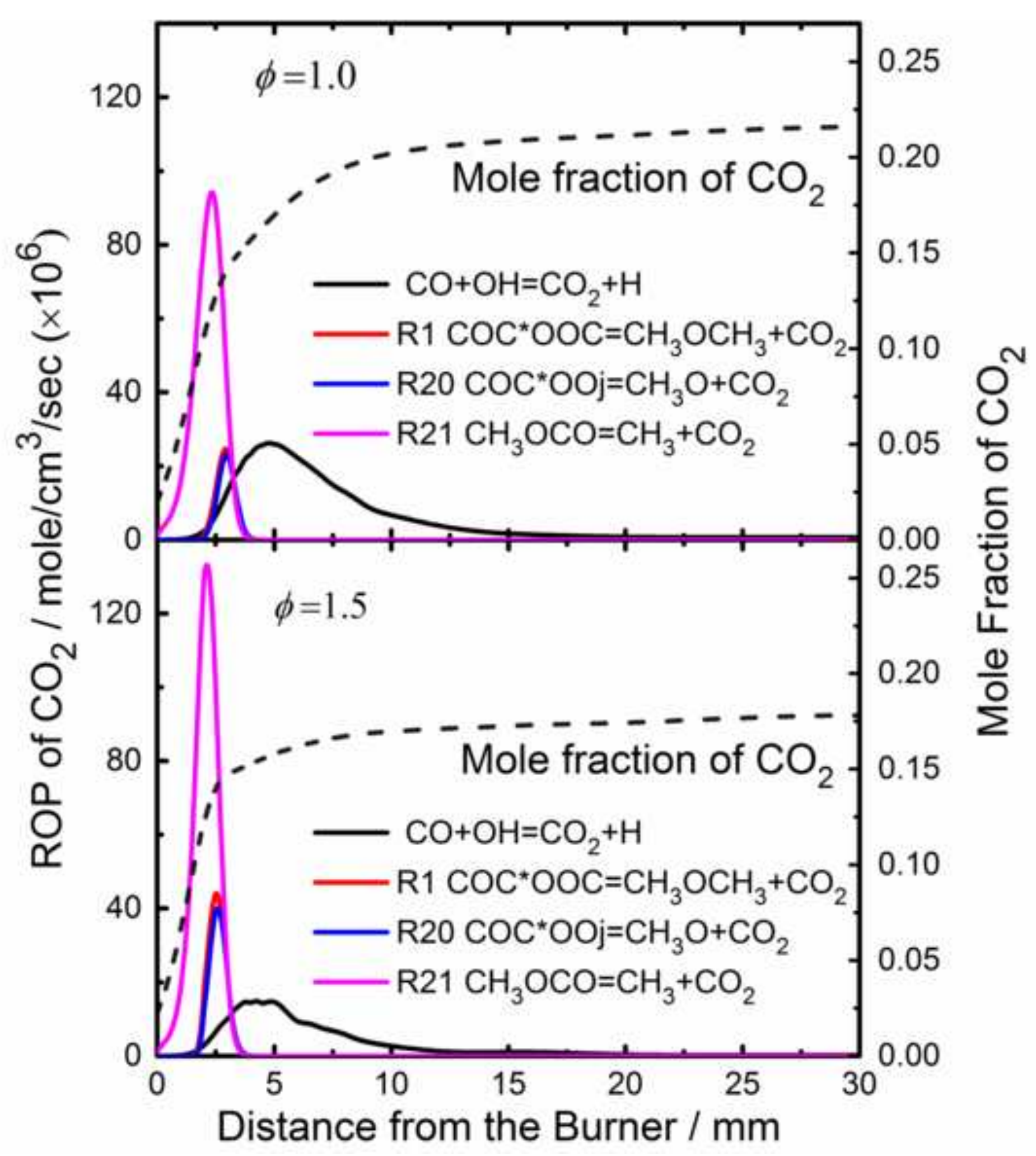



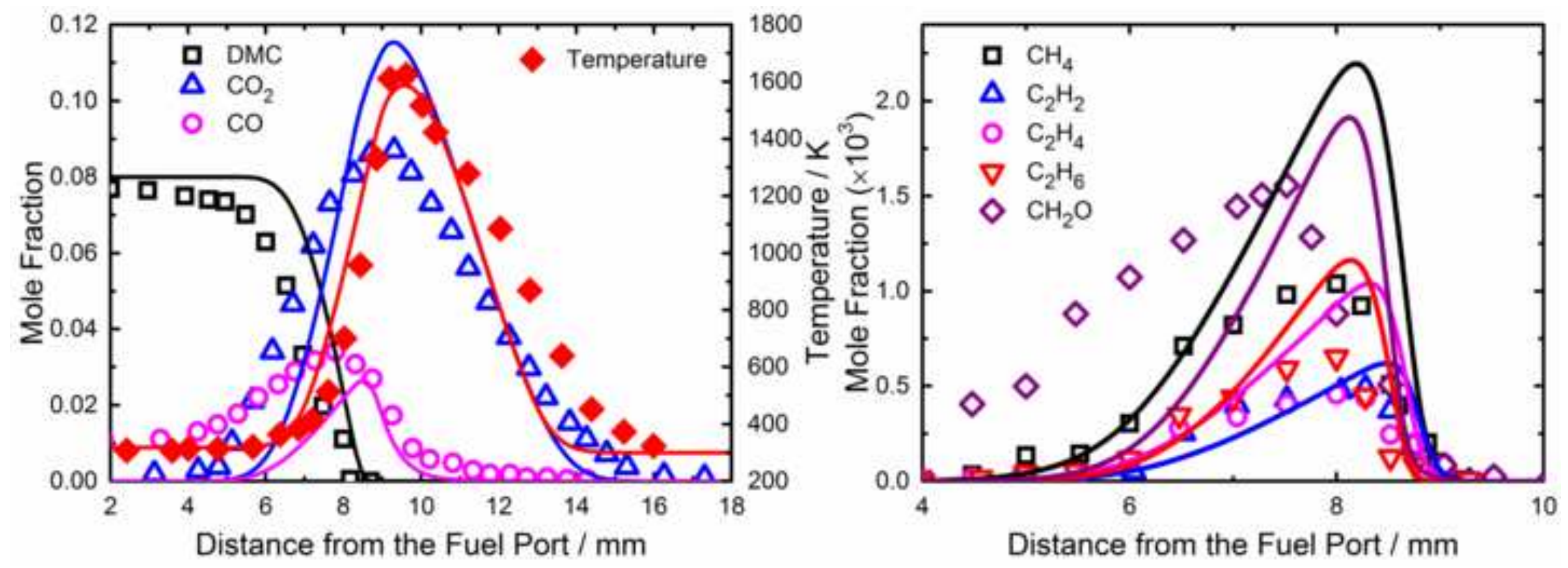


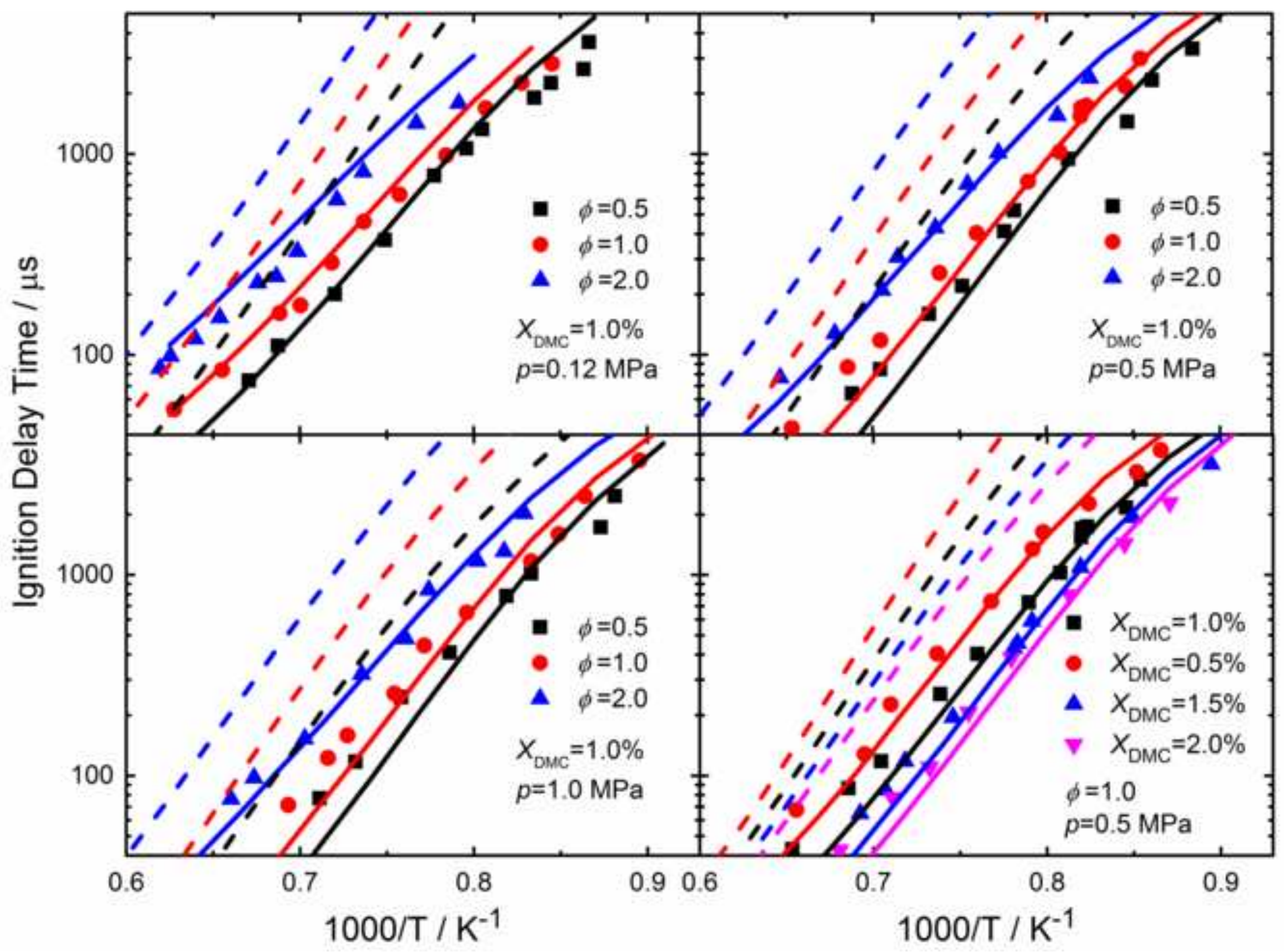



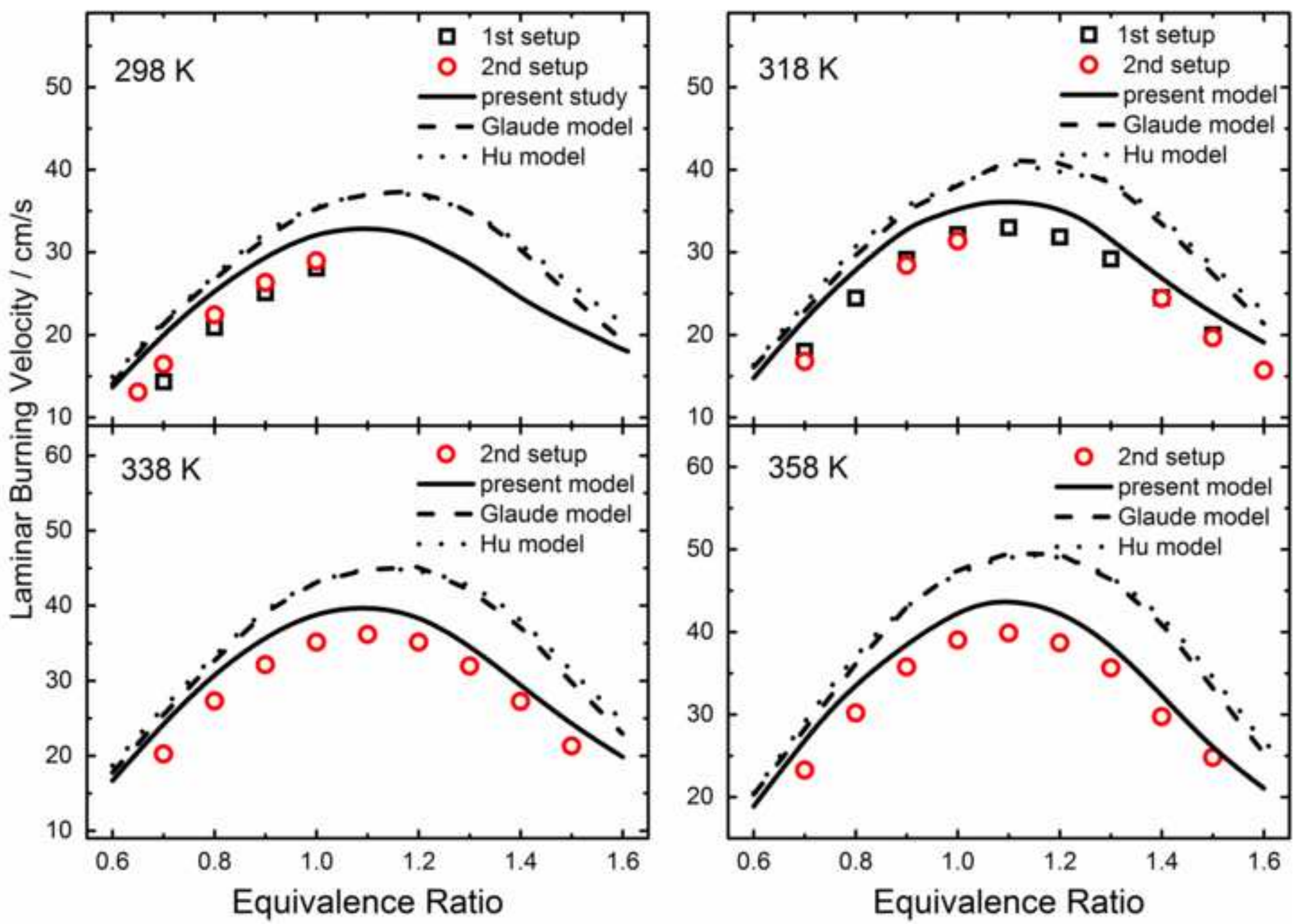